\title{
Ueber das Lackfarbenwerden der rothen Blutscheiben.
}

\author{
I. Mittheilung. \\ Von \\ Dr. Hans Koeppe, Giessen.
}

(Mit 1 Textfigur.)

Aufhellung, Lackfarben- oder Lackigwerden des Blutes - Auflösung der rothen Blutscheiben - Schmelzbarkeit der rothen Blutkörperchen - Austreten von Hämoglobin aus denselben - Blutfarbstoff-Austritt - Hämocytolyse - Hämolyse - bezeichnen diese verschiedenen Ausdrücke alle denselben Vorgang?

Ist dieser Vorgang immer durch die gleiche oder verschiedene Ursachen bedingt? Wirken blutkörperchenzerstörende Stoffe, Hämolysine, globulicide Stoffe, Blutgifte, alle in der gleichen Art und Weise auf die rothen Blutscheiben ein, oder besteht überhaupt ke in innerer Zusammenhang zwischen diesen verschiedenen Stoffen?

Diese Fragen mögen Manchem recht überflüssig dünken, denn in denselben scheinen "zweifellos ganz versehiedene" Dinge kritiklos in Zusammenhang gebracht zu sein. Doch ist dem nicht so. Alle mit diesen verschiedenen Namen bezeichneten Vorgänge haben ein Gemeinsames, eben die sinnfällige Erscheinung des Lackfarbenwerdens. Für dieses Lackfarbenwerden - Blutfarbstoffaustritt - werden, wie aus den verschiedenen Namen hervorgeht, verschiedene Ursachen geltend gemacht, ohne dass bisher auch nur für einen einzigen Fall über diesen Vorgang des Lackfarbenwerdens selbst eine bestimmte Vorstellung bestünde. Es ist da wohl leicht möglich, dass in manchen Fällen ein neues, besonderes ursächliches Moment angenommen wird, während die Erscheinung durch ein anderes, schon bekanntes Moment bedingt ist, was nicht erkannt wurde, weil auch von diesem die Grundursache noch nicht 
klar zu Tage liegt. Andererseits, wenn sieh in ganz bestimmten Fällen für die Erseheinung des Lackfarbenwerdens der rothen Blutscheiben eine bestimmte physikalische oder chemische Ursache feststellen lässt, dann kann durch geeignete Versuchsanordnung diese Ursache bei Untersuchungen über die Ursache des Lackfarbenwerdens in anderen Fällen mit Sicherheit ausgeschaltet werden.

Umfassende Untersuchungen über das Lackfarbenwerden der rothen Blutscheiben sind ein dringendes Bedürfniss, um über diesen Vorgang bestimmte und allgemeinere Vorstellungen zu gewinnen.

Ich hoffe, in dem folgenden Bericht über einen Theil meiner Untersuchungen schon jetzt Einiges zur Klärung dieser Fragen zu bringen, die in demselben mir wohlbekannten Lücken aber bald auszufüllen.

Wenn Rollett ${ }^{1}$ ) noch im Jahre 1900 erklärt: "Ich muss Gryns ${ }^{2}$ ) vollkommen zustimmen, wenn er sagt: Das Austreten von Hämoglobin ist eine noch nicht genügend erklärte Erscheinung," so muss dem in dieser allgemeinen Fassung wohl zugestimmt werden, allein, in einem besonderen Falle, dem Lackfarbenwerden des Blutes dureh Wasser, dürfte an der Richtigkeit $\mathrm{mein} \mathrm{er}^{3}$ ) Erklärung durch den Unterschied des osmotischen Drucks inner- und ausserhalb der rothen Blutscheiben wohl nicht mehr zu zweifeln sein. Zwar, auch v. Limbeck ${ }^{4}$ ) stimmt derselben 1896 nicht vollkommen zu: "Wenn sich Hamburger und mit ihm Koeppe nach wie vor auf den Standpunkt stellt, in dem endlichen Austritt des Blutfarbstoffs aus den Erythrocyten eine osmotische, d. h. nach rein physikalischen Gesetzen verlaufende Erscheinung zu sehen, so führt der Erstere u. A. selbst Thatsachen an,

1) A. Rollett, Elektrische und thermische Einwirkangen auf das Blut und die Structur der rothen Blutkörperchen. Arch. f. d. ges. Physiologie Bd. 82 S. 259. 1900.

2) G. Gryns, Ueber den Einfluss gelöster Stoffe auf die rothen Blutzellen, in Verbindung mit den Erscheinungen der Osmose und Diffusion. Arch. f. d. ges. Physiologie Bd. 63. 1896.

3) H. Koeppe, Ueber den Quellungsgrad der rothen Blutscheiben durch äquimolekulare Salzlösungen und über den osmotischen Druck des Blutplasmas. Archiv f. Anatomie u. Physiologie 1895. - Derselbe, Ueber den osmotischen Druck des Blutplasmas und die Bildung der Salzsäure im Magen. Archiv f. d. ges. Physiologie Bd. 62. 1896. - Derselbe, Der osmotische Druck als Ursache des Stoffaustausches zwischen rothen Blutkörperchen und Salzlösungen. Arch. f. d. ges. Physiologie Bd. 67. 1897.

4) v. Limbeck, Klinische Pathologie des Blutes S. 162. 1896. 
welche ihm selbst nur schwer, mir kaum mit dieser Auffassnng vereinbar erscheinen." Allein, inzwischen haben sich die Ansichten geklärt. „Bei der Auflösung der Erythrocyten durch Wasser handelt es sich bekanntlich um ein Gebiet, das zu den beststudirten der Medicin gehört", sagt kürzlich P. Ehrlich") in einer Abhandlung. Meine Auffassung uber das Lackfarbenwerden rother Blutseheiben in destillirtem Wasser habe ich schon 1897 (1. c. S. 190 u. f.) ausführlich dargelegt und werde später darauf zurückkommen, da dieselbe den Ausgangspunkt meiner Untersuchungen bildet. Ha mburger's ${ }^{2}$ ) Vorstellung aber weicht von der meinigen nicht unwesentlich $a b$. Es ist nicht leicht, Hamburger's Gedankengang in der langen Reihe seiner Arbeiten vom Jahre 1886 bis 1902 zu folgen. Die Zusammenstellung des Hämoglobinaustritts aus den rothen Blutscheiben mit der Plasmolyse bei Pflanzenzellen erscheint mir recht unglücklich und bringt Schwierigkeiten in die Auffassung, welche nicht bestehen.

In seiner ersten Publication (1886) steht $\mathrm{H}$ a m bu r ger vollständig auf de Vries'schem Standpunkt und glaubt an einen Zusammenhang der Plasmolyse in Pflanzenzellen mit den bei Blutkörperchen wahrgenommenen Erscheinungen. Von dieser Anschaung hat sich Hamburger nicht losmachen können und gelangt derselben zu Liebe zu seiner Auffassung und Betonung der Structur der rothen Blutscheiben, wodurch das Verständniss des Vorganges, anstatt erleichtert, vielmehr complicirt wird, so dass sich Rollett (l. c. S. 257) zu dem Ausspruch veranlasst sieht: „der Hämoglobinaustritt aus den Blutkörperehen, den Hamburger in einer mir niemals vollkommen verständlich gewordenen Weise mit der Plasmolyse von de Vries parallel stellte -."

Am verhältnissmässig klarsten spricht $\mathrm{H}$ a m burger seine Auffassung in seinem Buche S. 167 und 391 aus. Das unbestrittene Verdienst Hamburger's auf diesem Gebiete erlaubt nicht, seine Auffassung mit Stillschwejgen zu übergehen; ich gebe dieselbe desshalb ausführlich als Einleitung wieder, um alsdann die Differenz zwischen Hamburger's und meiner Auffassung klarzulegen und später zu zeigen, dass meine einfachere Vorstellung über den Vorgang zur Erklärung genügt und auch geeigneter ist, an der Hand derselben tiefer in die Verbältnisse einzudringen.

1) P. Ehrlich, Münch. med. Wochenschr. 1908 S.1431. Toxin und Antitoxin.

2) Hamburger, Osmotischer Druck und Ionenlehre S. 187 and 391. Wiesbaden 1902. 


\section{Hamburger's Hypothese.}

„Fragt man, wie es zu erklären ist, dass die isotonischen Coëfficienten von de Vries bei den Blutkörperchen wiedergefunden werden, so ist die Antwort mit Hülfe der folgenden Hypothese nicht schwer zu geben.

Stellen wir uns vor, das Blutkörperchen bestünde aus einem protoplasmatischen Netz, in dessen Maschen sich ein gefärbter, mehr oder weniger flüssiger Inhalt befindet. Dann ist es a usschliesslich dieser intraglobulare Inhalt, welcher die wasseranziehende Kraft des Blutkörperchens repräsentirt; das protoplasmatische Netz ist nicht daranbetheiligt.

Weiter stellen wir uns vor, dass die äusere protoplasmatische Begrenzung permeabel für Wasser sei, nicht aber für die genanten Krystalloide.

Bringen wir nun etwas Blut in eine schwache $\mathrm{KNO}_{3}$-Lösung, dann werden die Blutkörperehen so lange Wasser anziehen, bis ihr flüssiger Inhalt dasselbe wasseranziehende Vermögen repräsentirt, denselben asmotischen Druck besitzt wie die umgebende $\mathrm{KNO}_{3}$ Lösung. Die $\mathrm{KNO}_{2}$-Lösung kann nun so schwach sein, dass einige Blutkörperchen dermaassen quellen, dass sie ihren Farbstoff verlieren oder, besser gesagt, ihren gefürbten Inhalt über den nunmehr zwisehen den Maschen übrig gebliebenen Raum und die umgebende $\mathrm{KNO}_{3}$ Lösung vertheilen. Nach dem Absetzen der anderen Blutkörperchen zeigt dann die obere Flüssigkeit einen Stich in's Rothe."

"Was man bis jetzt mit Resistenz der rothen Blutkörperchen gegen verdünnte Salzlösungen bezeichnet hat, ist eine complexe Grösse. Die zahlreichen Bestimmungen dieses Werthes, die man für klinische und auch für pharmakologische Zwecke ausgeführt hat, sind trotz der grossen Schärfe der dazu benutzten sogenannten Blutkörperchenmethode bis jetzt wenig fruchtbar gewesen. Das ist darauf zurückzuführen, dass man sich von der Complicirtheit der hier in Frage kommenden Haupterscheinung (Blutfarbstoffaustritt) keine Rechenschaft gegeben hat und somit auch nicht eruirt hat, um welche Factoren es sich hierbei handelt. Um das mit Erfolg durchführen zu können, ist es aber unerlässlich, sich von der Structur des Blutkörperchens eine möglichst präcise Vorstellung zu machen. Leider stehen wir in Beziehung hierauf noch ganz auf dem Boden der Hypothese. 
Zwar baben die neueren, im Lichte der physikalischen Chemie ausgeführten Untersuchungen wichtige Thatsachen über die Eigenschaften der protoplasmatischen Begrenzung an's Licht gebracht, auch klärten sie uns über die Wechselwirkung zwischen Inhalt und natürlicher Umgebung des Blutkörperchens unter dem Einfluss von Kohlensäure, Spuren von Alkali und Säure u. s. w. auf. Doch kann man leider nicht behaupten; dass diese Forschungen über die Art und Weise Aufschluss gegeben hätten, wie das Hämoglobin und der Zellinhalt im Allgemeinen in der Zelle vertheilt ist. Doch empfindet man gerade in Folge dieser Untersuchungen, namentlich bei der Deutung vieler der betreffenden Erscheinungen, mehr als je das Bedürfniss, sich von der Structur eine klare Vorstellung zu machen, und die Aufstellung einer Hypothese ist auch für die weitere Entwicklung der bereits gewonnenen Kenntnisse unumgänglich nöthig.

Desshalb habe ich auch versucht, an der Hand einer solchen Hypothese, auf die ich mich auch schon in früheren Abschnitten dieses Buches gestützt habe, den Begriff der ,Resistenz der Blutkörperchen gegen Salzlösungen' zu analysiren.

Ich denke mir das Blutkörperchen aus einem protoplasmatischen Netz bestehend, in dessen geschlossenen oder nicht geschlossenen Maschen sich eine flüssige oder halbflüssige, rothgefärbte Masse befindet. Die letztere ist es, die das wasseranziehende Vermögen des Blutkörperchens repräsentirt; das protoplasmatische Netz ist hieran nicht betheiligt. Man stelle sich nun vor, dass das Blutkörperchen aus seinem natürlichen Medium in eine verdünnte, hypisotonische Lösung gebracht wird. Es wird dann der rothe Mascheninhalt durch die semipermeable Protoplasmabegrenzung hindurch Wasser anziehen und an Volumen zunehmen. Ob bei dieser Volumenzunahme die Protoplasmabegrenzung den gefärbten Inhalt durchlassen wird, hängt für eine bestimmte Salzlösung zunächst von dem Wasseranziehungsvermögen des Blutkörpercheninhalts ab. Je grösser dieses ist, um so bedeutender wird die Volumenzunahme dieses Mascheninbalts (intraglobularen Inhalts $v_{1}$ ) sein. Ferner ist auch dessen procentuales Volumen ein wichtiger Factor, denn je grösser dasselbe im normalen Blutkörperchen ist, um so grösser muss auch die absolute Volumvermehrung nach Einwirkung der verdünnten Salzlösung sein. Schliesslich wird der Durchtritt des intraglobularen Inhalts bei einer bestimmten Volumzunahme von der Natur (Resistenz) des Protoplasmas abhängen." 
Im Wesentlichen hat also Hamburger seine Anschauungen beibehalten: die Verhältnisse, wie sie bei Plasmolyse der Pflanzenzellen beobachtet sind, einfach auf die rothen Blutscheiben übertragen; doch erhalten dieselben hier einen ganz hypothetischen Charakter, da an den rothen Blutscheiben die Plasmolyse nicht beobach tet werden kann wie bei den Pflanzenzellen.

Augenscheinlich kommt Hamburger zu der Annahme eines protoplasmatischen Netzes in den rothen Blutscheiben in Analogie mit der Cellulosebegrenzung der Pflanzenzellen; die Cellulosewände der Pflanzenzellen haben mit der Plasmolyse nichts zu thun, sie quellen und schrumpfen nicht, lassen Wasser und Salze durch sich hindurch, - genau so Hamburger's „protoplasmatisches Netz ${ }^{4}$. Innerbalb der Cellulosewände liegt bei den Pflanzen der Protoplast, der für gewöhnlich dem Cellulosegerüst anliegt, sich aber von demselben zurückzicht, wenn ihm Wasser entzogen wird; das Plasma löst sich von der Cellulosewand ab; daher der Name Plasmolyse. Das Protoplasma hat die Eigenschaft, semipermeabel zu sein, sei es in toto oder nur in seiner Grenzschicht. Dem Plasmaschlauch der Pflanzenzelle entspricht Hamburger's "intraglobularer Inhalt" der rothen Blutscheiben; dieser ist auch semipermeabel, d. h. für Krystalloide nicht durchlässig, wohl aber für Wasser; dieser quillt und schrumpft wie der Pflanzenplasmaschlauch, doch lässt sich hier Plasmolyse nicht beobachten, da Hamburger's hypothetisches Protoplasmagerüst nicht sichtbar ist, wie das der Pflanzenzelle. Die Bezeichnung "protoplasmatisches" Netz schliesst schon eine Charakterisirung in sich ein, welche bei der hypothetischen Natur desselben mir nicht gerechtfertigt erscheint. Einmal gibt $\mathrm{H}$ a mburger absolut keinen Anhaltspunkt dafür, warum das Netz aus Protoplasma bestehen soll; dann aber erscheint es ungereimt, wenn von einem protoplasmatischen Netz angenommen wird, dass es am Quellen und Schrumpfen nicht Theil nimmt (keine wasseranziehende Kraft hat), während im Allgemeinen als besondere Eigenschaft des Protoplasmas eben die Semipermeabilität angenommen wird.

Sehen wir nun von dem "protoplasmatischen Netz" ab, so bleibt der "intraglobulare Inhalt" der rothen Blutscheiben, dessen äussere protoplasmatische Begrenzung die Eigenschaft besitzt, semipermeabel zu sein. Also das, was physikalisch-chemisch als "semipermeable Wand" bezeichnet wird, ist diese protoplasmatische Begrenzung des intraglobularen Inhalts der rothen Blutscheiben. Bei 
physikalisch-chemischer Betrachtung kommt demnach das protoplasmatische Netz gar nicht in Frage; es ist daher für unsere Zwecke überflüssig, über diese Hypothese zu discutiren. Schalten wir aber diese Hypothese von dem protoplasmatischen Netz aus, so bleibt der "intraglobulare Inbalt" mit seiner semipermeablen Wand, und ein Unterschied zwischen Hamburger's Auffassung der hierauf bezüglichen Verhältnisse und meinen 1897 dargelegten Anschauungen besteht nicht.

Wir werden aber sehen, dass auch ohne die Hamburgersche Hypothese über die Structur der rothen Blutscheiben eine weitere Entwicklung unserer Kenninisse über die rothen Blutkörperchen möglich ist, ja, dass wir auf Grund der einen, höchst einfachen, mit den bekannten Thatsachen in gutem Einklang stehenden Annahme von der Halbdurchlässigkeit der "Wand" der rothen Blutscheiben zu wichtigen Schlüssen über die chemische Natur dieser "Wand" gelangen.

\section{Lackfarbenwerden rother Blutscheiben durch Wasser.}

Auf die einfachste Weise erzielt man Lackfarbenwerden des Blutes durch Zusatz genügender Mengen von Wasser zum Blute. Der Vorgang tritt hierbei in typischer Weise in Erscheinung:

Unverletzte rothe Blutscheiben, wenn auch in ihrer Form mehr oder weniger verändert, verleiben einer Flüssigkeit, in der sie suspendirt sind, eine rothe Deckfarbe, d. h. das Blutgemisch ist vollkommen undurchsichtig auch in dünner Schicht. Dass die rothen Blutkörperchen noch vollkommen als solche erhalten sind, lässt sich unter dem Mikroskop leicht feststellen, geht aber auch daraus hervor, dass sie in solchen Flüssigkeiten zu Boden sinken, sedimentiren; die über dem Sediment stehende Flüssigkeit ist in solchen Fällen klar durchsichtig, hat ihre Eigenfarbe. Wird nun zu einer solchen Blutkörperchensuspension (in Serum oder sonst geeigneter Flüssigkeit) Wasser im Ueberschuss zugesetzt, so geht eine auffallende Veränderung der Farbe des Gemisches vor sich: die Farbe wird dunkler roth, aber das Ganze wird durchscheinend, transparent, das Gemisch hellt sich im durchfallenden Licht auf, das Blut ist "] ackfarben" geworden. Mikroskopisch ist von den rothen Blutscheiben nichts mehr zu finden. Das ganze Gemisch ist gleichmässig roth gefärbt, wenn 
auch etwas dunkler, doch noch vollkommen hämoglobinfarbig. Sedimentbildung ist nicht zu sehen, ebensowenig eine Trübung oder ein Niederschlag.

Durch den Wasserzusatz werden also die rothen Blutscheiben als solche zerstört; sie werden aufgelöst, ihres Hämoglobins beraubt, das nun in die umgebende Flüssigkeit diffundirte, diese roth färbte.

Das Wasser wirkt demnach hämolytisch, es ist als ein „Blutgift" (Hedin) zu bezeichnen u.s. w. Wodurch nun aber wirkt das Wasser in so zerstörender Weise auf die Blutscheiben ein? in welchen seiner Eigenschaften liegt dieses blutkörperschädigende Moment?

Eine der wesentlichsten Aenderungen, welche das rothe Blutkörperchen erleidet, wenn Blut aus der Deckfarbe in Lackfarbe umschlägt, ist das Aufgeben der Form. Alle Momente, welche die Form der rothen Blutscheiben beeinflussen, müssen desshalb bei dem Suchen nach der Ursache des Lackfarbenwerdens mit in Betracht gezogen werden. Als hervorragend geeignet, Volumen-und damit auch F ormänd erungen der rothen Blutscheiben nachzuweisen, hat sich der Hämatokrit bewiesen, und die beim Arbeiten mit demselben gewonnenen Erfahrungen, sowie die auf Grund derselben gewonnenen Vorstellungen über die rothen Blutscheiben können als Ausgang der Betrachtungen über das Zustandekommen des Lackfarbenwerdens des Blutes genommen werden.

Aus den Versuchen mit dem Hämatokriten ergab sich, dass das Volumen der rothen Blutscheiben abbängt von der Concentration der Lösung, in welcher sie suspendirt sind. In derselben Concentration behalten sie ibr Volumen; mit Aenderung der Concentration ändert sich auch das Volumen der rothen Blutscheiben, und zwar vollkommen gesetzmässig entsprechend der Concentrationsänderung: das Volumen wird kleiner, wenn die Concentration grösser wird, und umgekehrt. Lösungen verschiedener Stoffe, in denen die rothen Blutscheiben gleiches Volumen zeigten, erwiesen sich als Lösungen von gleichem osmotischen Druck.

Durch Vergleichung solcher nach der Hämatokritmethode ermittelter isosmotischer Lösungen liess sich, in guter Uebereinstimmung mit den Ergebnissen physikalischer Methoden, der D is s ociationscoëfficient für verschiedene Salze in wässeriger Lösung bestimmen, und die $\mathrm{Abh}$ ängigkeit dieses Coëfficienten von der Concentration der Lösung nachweisen; durch 
Mischung isosmotischer Lösungen konnte der Finfluss und die Geltung des Henry-Dalton'schen Gesetzes klar erkannt werden; kurz, es besteht kein Zweifel darüber, dass Quellen und Schrumpfen der rothen Blutscheiben gesetzmässig erfolgt, nämlich nach den Gesetzen des osmotischen Drucks, dieser also in erster Linie für das Volumen der rothen Blutscheiben maassgebend ist.

Aus dieser Abhängigkeit des Volumens der rothen Blutkörperchen $\vee 0 \mathrm{~m}$ osmotischen Druck der Lösung, in welcher sie suspendirt sind, musste weiter gefolgert werden, dass die rothen Blutscheiben sich genau so verhalten, als wenn sie von einer halbdurchlässigen Membran umgeben wären, oder auch mit anderen Worten: dass die rothen Blutscheiben Einrichtungen besitzen, welche den physikalischen halbdurchlässigen Wänden entsprechen ${ }^{1}$ ).

Auf Grund dieser Untersuchungsresultate gelangen wir $z a$ folgender Vorstellung des Vorganges beim Quellen und Schrumpfen der rothen Blutscheiben:

Die Blutzelle verhält sich wie eine mit einer Lösung gefüllte Blase, welche von einer halbdurchlässigen Membran umgeben ist. Durch diese halbdurchlässige Wand dringt Wasser von aussen nach innen oder umgekehrt, je nachdem der osmotische Druck in der Blase grösser oder kleiner ist als der osmotische Druck der Lösung, in welcher die Blase schwimmt. Je mehr der osmotische Druck der Aussenlösung sinkt, desto mehr Wasser dringt in die Blase, desto mehr schwillt diese an. Hat die halbdurchlässige Wand der Blase auch eine noch so grosse Elasticität, einmal wird eine Grenze erreicht sein, wo die Blase platzt und ihren Inhalt in die umgebende Lösung ergiesst. Die Erniedrigung des osmotischen Drucks der Aussenlösung wird durch einfachen Zusatz von Wasser bewirkt, dessen osmotischer Druck gleich Null ist. Dadurch also, dass ein Zusatz von Wasser den osmotischen Druck der Aussenlösung erniedrigt, ist er die Ursache davon, dass die Blase platzt, die Blutzelle sich auflöst.

Weil der osmotische Druck des Wassers gleich Null ist, müsste

1) Koeppe, Physikalische Chemie in der Medicin S. 74. A. Hölder, Wien 1900. S. 74. 
eine rothe Blutzelle, deren Zellflüssigkeit einen bestimmten osmotischen Druck hat, in dem Wasser so lange quellen, bis der osmotische Druck ihres Inhalts auch gleich Null wird, das ist aber nicht möglich, weil die halbdurchlässige Membran der Zelle schon vorher diese ihre Eigenschaft verliert und den Zellinhalt nicht mehr von der Aussenflüssigkeit trennen und schützen kann, in Folge dessen unter anderen das Hämoglobin der Zelle sich in der Aussenflüssigkeit auflöst. Das ist aber nichts Anderes als: das Blut ist lackfarben geworden.

Die Ursache des Lackfarbenwerdens von Blut in Wasser ist demnach die Zerstörung der halbdarchlässigen Wand der rothen Blutscheiben in Folge des übergrossen Unterschieds des osmotischen Drucks innen und ausserhalb der Blutzellen.

Die Richtigkeit dieser Erklärung des Lackfarbenwerdens von Blut in Wasser ergibt sich auch aus noch anderen Ueberlegungen, welche demnach darthun, dass die Ursache eben diese mechanische ist, nicht in der chemischen Natur des Wassers liegt.

Erhöhen wir den osmotischen Druck des Wassers, indem wir gewisse Salze oder andere Stoffe in demselben auflösen, bis zu dem Drucke, der in den rothen Blutseheiben vorhanden ist, so heben wir den vorher bestehenden Unterschied des osmotischen Drucks zwischen aussen und innen auf, und die Folge davon ist: das Blut wird nicht lackfarben. Durch den Zusatz des Salzes ist aber doch das Wasser an sich in keiner Weise verändert worden, sondern nur der osmotische Druck; demnach bewirkte auch nicht das Wasser das Lackfarbenwerden, sondern der Unterschied des osmotischen Drucks. Wählen wir zur Erhöhung des osmotischen Drucks des Wassers einen Stoff, welcher die Wand der rothen Blutscheiben durebdringt, also auf dieselben keinen Druck ausubt, so tritt doch Lackfarbenwerden des Blutes ein, trotzdem innen und aussen gleicher osmotischer Druck herrscht, weil der äussere osmotische Druck nicht zur Wirkung kommt, mithin auch für die Wand ein Unterschied des osmotischen Drucks innen und aussen besteht, in Folge dessen sie zerstört wird. Ein solcher Stoff ist Harnst off. (Die Durchgängigkeit der rothen Blutscheiben für Harnstoff ist von mir zuerst [dieses Archiy Bd. 62 S. 576. 1896] im Zusammenhang mit dem Lackfarbenwerden des Blutes besprochen worden [ausführlicher dieses Archiv Bi. 67. 1897].) Wenn also der Harnstoff die Wirkung des Wassers, Blut lackfarben zu machen, 
nicht aufhebt, so ist der Harnstoff darum doch ke in Stoff, welcher Blut lackfarben macht, welcher in Folge seiner chemischen Natur oder sonstigen Eigenschaften den Austritt von Hämoglobin aus den Blutzellen bedingt. Der Harnstoff ist ohne jeden Einfluss auf das Lackfarbenwerden rother Blutscheiben. Das zeigt sich auch daraus: wenn Harnstoff in Serum oder irgend einer Salzlösung, in welcher die rothen Blutscheiben intact bleiben, gelöst wird, so bleiben die rothen Blutseheiben in dieser Lösung auch intact; es tritt keine Lackfärbung ein.

Diese Ueberlegungen führen zu zwei wichtigen Ergebnissen für weitere Untersuchungen über die Ursachen des Lackfarbenwerdens von Blut. Wir haben in jedem Fall, in dem wir Lackfarbenwerden beobachten, erstens zu fragen: ist vielleicht, wie heim Wasser, der Unterschied z wischen osmotischem Druck innen und aussen die Ursache? und zweitens, wenn innen und aussen von den Blutscheiben Gleichheit des osmotischen Drucks besteht: kommt der ä u s s e r e osmotische Druck auch wirklich als solcher zur Geltung? Wir müssen demnach ganz genau nicht nur den Stoff kennen, den wir auf seine Fähigkeit, Blutkörperchen lackfarben zu machen, prüfen wollen, sondern wir haben auch in erster Linie dafür zu sorgen, dass bei dieser Untersuchung die Blutscheiben in einer Lösung suspendirt sind, in welcher die Blutscheiben nicht lackfarben werden, die schädigende Wirkung des Wassers ausgeschlossen ist.

Wie erklärt sich z. B. das Lackfarbenwerden des Blutes in Folge wiederholten Gefrierens und Aufthauens von Blut?

Es sind hierbei die Blutscheiben im Serum suspendirt, welches den gleichen osmotischen Druck hat, wie er innerhalb der Blutzellen herrscht, und der Aussendruck kommt auch als solcher zur Geltung; das Blut wird nicht lackfarben. Durch das Gefrieren und Aufthauen wird aber der osmotische Druck innen und aussen nich t geändert; vor dem Gefrieren und nach dem Aufthauen ist der osmotische Druck der gleiche. Trotzdem tritt Lackfärbung ein! Der Grund für die Lackfärbung ist hier aber doch ein mechanischer. Allerdings ist der osmotische Druck des Serums vor dem Gefrieren und nach dem Aufthauen der gleiche, aber $z$ wischen diesen beiden Zeitpunkten besteht eine Periode, wo die Gleichgewichtsverhältnisse sich gewaltig verschoben hatten. Beim Gefrieren einer Lösung gefriert das Lösungsmittel in reiner 
Form aus; wie beim Krystallisiren die Krystalle chemisch rein anschiessen, so scheiden sich auch beim Gefrieren einer wässerigen Lösung Krystalle von chemisch reinem Wasser aus. Als Eis wirken sie vielleicht auch schon zerstörend auf die Blutscheiben; sobald sie aber schmelzen, vergeht eine Zeit, bis im Schmelzwasser die Salze sich wieder gelöst haben, und diese Zeit genügt, zwischen Innen- und Aussenflüssigkeit der rothen Blutscheiben die osmotische Druckdifferenz eintreten zu lassen, in Folge deren Lackfärbung eintritt. Die Ursache des Lackfarbenwerdens beim Gefrieren und Aufthauen von Blut ist also auch eine mechanische, nämlich die gleiche wie beim Wasser.

\section{Die "semipermeable Wand" der rothen Blutscheiben.}

Aus dem Vorbergehenden haben wir gesehen, dass für das Eintreten und Nichteintreten der Lackfärbung der Zustand der "halbdurchlässigen Wand" der rothen Blutscheiben in gewissem Sinne das ausschlaggebende Moment ist. Diese Wand erhält die Blutzellen; ist sie verletzt, muss der Inhalt sich der Umgebung mittheilen. Beim Zusatz von Wasser zu Blut wird die "Wand" durch mechanische Gewalt zerstört; es ist doch nun die nächste Frage die: Gibt es nicht noch andere Einflüsse, welche auf die „Wand" zerstörend einwirken?

Bevor wir der Beantwortung dieser Frage nähertreten, ist es nothwendig, dass wir uns noch ein Mal genau klar machen, was wir eigentlich Positives über diese „Wand" wissen.

Da muss vor Allem ausdrücklich hervorgehoben werden, dass thatsächlich durch die Hämatokritversuche nicht mehr erwiesen wurde, als in den bedingten Sätzen niedergelegt ist: Die rothen Blutscheiben verhalten sich so, als wenn sie von einer halbdurchlässigen Membran umgeben wären. Wenn sonst nun schon kurzer Hand die "halbdurchlässigen Wände" als im Organismus wirklich vorhandene bezeichnet werden, so ist dies doch nur in diesem bedingten Sinne zu verstehen, nämlich unter vorläufig ${ }^{1}$ ) "vollständigem Beiseitelassen irgend einer Vorstellung von der Form, Ausdehnung oder chemischen Natur dieser,Wände" ". Hierin liegt eine gewisse Gefahr: wir operiren leicht mit dem Begriff "halb-

1) Koeppe, 1. c. S. 34 . 
durchlässige Wand" als etwas nicht bloss dem Sinne, sondern auch dem Buchstaben nach Bewiesenem, erinnern uns nicht mehr des Hypothetischen dieses Begriffes und identificiren wo möglich die „Wand" mit "Membran". Eine solche Auslegung würde dann folgerichtig denken, ich stellte mir ein rothes Blutkörperchen als eine von einer halbdurchlässigen Membran umkleidete Hämoglobinlösung (mit einigen Salzen und Eiweiss) vor. Das ist ganz und gar nicht der Fall! Die Natur und das Wesen der „halbdurchlässigen Membranen ", selbst der künstlichen, sind auch den Physikochemikern ${ }^{1}$ ) noch nicht klar; wie sollten wir aus physikalisch-chemischen Calculs eine Vorstellung über Bau oder Constitution der halbdurchlässigen Wände der Zellen gewinnen können?

L. Hermann (Arch. f. d. ges. Physiologie Bd. 91 S. 186. 1902) schreibt zu dieser Frage: „Allerdings verhalten sich nach neueren Untersuchungen die rothen Blutkörperchen genau so, als wenn sie von einer nur für Wasser durchlässigen Membran umschlossen wären. Aber man kann doch eine wirkliche Membran dieser Art unmöglich annehmen, und welche Oberflächeneigenschaften die in Rede stehenden Erscheinungen bedingen, ist noch völlig in Dunkel gehüllt."

Meine Ausführungen decken sich mit dem ersten Satze. Allein, in dem zweiten Satze steht mehr, als die Versuche aussagen. Wenn auch die Existenz einer Membran durch den Nachweis einer "semipermeablen Wand" nicht erbracht ist, so geht daraus noch nicht hervor, dass eine wirkliche Membran dieser Art un möglich ist.

Die eventuelle Erklärung der Erscheinungen durch Oberflächeneigenschaften ist schon eine viel speciellere als durch die einfache Annahme der "halbdurchlässigen Wand". Mit dem Begriff der halbdurchlässigen Wand ist zur Zeit noch absolut keine Vorstellung von der Natur derselben zu verknüpfen nothwendig. Dass solche für Jeden einzeln bestehen und zulässiog sind, ist eine andere Frage. Viele werden mehrfache Vorstellungen sich gebildet haben; ich selbst bin schon zu bestimmten Vorstellungen gekommen, für welche ich aber erst theilweise experimentelle Grundlagen habe. Zwar ist für mich die Existenz einer "Membran" der rothen Blutscheiben durchaus nicht bewiesen, allein, ebensowenig habe ich die Ueberzeugung, dass die Existenz einer solchen unmöglich ist.

1) Van 't Hoff, Vorlesungen über theor. u. physik. Chemie. Chemische Statik S. 28. 1903. 
Trotz der Aussichtslosigkeit des Unterfangens, - es liegt jetzt die Nothwendigkeit vor, über die "halbdurchlässige Membran" der rothen Blutscheiben $\mathrm{mehr}$ zu erfahren, - wir müssen bestimmte Vorstellungen über das Wesen dieser "Wände" mit der räthselhaften wunderbaren Eigenschaft der "Halbdurchlässigkeit" zu gewinnen trachten.

Wenn unsere eingangs geschilderten Ueberlegungen klar darlegten, wie wichtig die "halbdurchlässige Wand" für das Eintreten oder Nichteintreten der Erscheinung des Lackfarbenwerdens ist, so müssen systematische Untersuchungen über die Bedingungen, unter welchen Lackfarbenwerden sicher und regelmässig zu erzielen ist, auch gewisse Schlüsse auf die "Wand" selbst zu ziehen gestatten. Fahren wir fort, Schritt für Schritt unsere theoretischen Schlüsse auf der Hypothese der "halbdurchlässigen Wand" weiter auszubauen, immer begleitet und controlirt durch Experimente, so müssen wir einmal dahin kommen, wo Theorie und Experiment endgültig übereinstimmen oder auseinandergehen! Von diesem Gesichtspunkte aus betrachtet, gewinnen die Forschungen über die Ursachen des Lackfarbenwerdens des Blutes natürlich ein weiteres, umfassenderes Interesse!

Kehren wir nun wieder zurück zum Ergebniss unserer ersten Ueberlegungen!

Die unverletzte Wand schützt den Inhalt der rothen Blutscheiben, bewahrt ihn vor der Auflösung in der umgebenden Flüssigkeit. Wird die Wand durch mechaniscbe Gewalt zerstört oder nur verletzt, so tritt Lackfarbenwerden des Blutes ein; es wird durch die mechanische Verletzung eben ihre specifische Eigenschaft der "Halbdurchlässigkeit" aufgehoben. Worin diese Eigenschaft besteht, wissen wir nicht; nicht selten wird sie als specifische Eigenschaft des "lebenden" Protoplasmas bezeichnet [z. B. nennt Gryns") die Erscheinung des Lackfarbenwerdens ein Zeichen des Absterbens oder wenigstens einer tiefgehenden Veränderung der Blutkörperchen]. Sobald die rothe Blutzelle aufhört, zu "leben", verliert sie die Eigenschaft, balbdurchlässig zu sein, und sie löst sich in der umgebenden Flüssigkeit auf. Stimmt das, so muss ein Gift, welches die rothen Blutscheiben tödtet, auch Lackfarbenwerden derselben bewirken. Es wäre demnach denkbar, dass auch ausser der mechanischen, durch

1) Gryns, Arch. f. d. ges. Physiol. Bd. 63 S. 97. 
osmotische Druckunterschiede wirkenden Kraft, zweitens ein hypothetischer Stoff Lackfarbenwerden der Blutscheiben bewirkt, welcher allein dadurch diesen Effect erreicht, dass er durch Vernichtung des "Lebens" der Blutzellen die Halbdurchlässigkeit derselben aufhebt, ohne dass er sonst in irgend einer Weise einen mechanischen oder chemischen Einfluss auf die einzelnen Bestandtheile der Blutscheiben ausübt. [Ich kann diesen Satz nicht niederschreiben, ohne zu bemerken, dass für mich ein solcher Stoff undenkbar ist. Etwas, das das "Leben" einer Zelle vernichtete, musste (meiner Auffassung nach) in irgend einer Weise mechanisch oder chemisch auf die Zelle eingewirkt haben.] Drittens ist es denkbar, dass die "Wand" der rothen Blutscheiben durch irgend einen $\mathrm{ch} \mathrm{e} \mathrm{m}$ is $\mathrm{ch}$ e n Einfluss ihre Halbdurchlässigkeit verliert, sei es, dass sie mit irgend einem Stoff eine Verbindung eingeht, welche die Eigenschaft der Semipermeabilität nicht besitzt, oder dass ihr durch einen Stoff Moleküle oder Molekülcomplexe entzogen werden, oder sonst wie.

Wenn es uns gelingen sollte, Stoffe aufzufinden, welche durch chemische Veränderung der Wand Lackfarbenwerden der Blutscheiben bewirken, so würde daraus ein weiterer Gewinn resultiren, nämlich der, dass wir irgend welche Vorstellung von der chemischen Natur der "W and" erlangen.

\section{Untersuchungsmethode.}

Bei der Prüfung des Einflusses irgend eines Stoffes auf die "halbdurchlässige Wand" der rothen Blutscheiben ist es nicht gleichgültig, in welcher Weise dabei verfahren wird. Zusatz des betreffenden Stoffes in Substanz oder in Lösung direct zum Blute hat versehiedene Nachtheile: eine gleichmässige Einwirkung wird so oder so nicht zu erzielen sein. Man müsste dazu die Blutkörperchen vom Serum isoliren, dem Serum die zu prüfenden Stoffe beigeben und nun wieder mit rothen Blutscheiben versetzen. Da fragt es sich nun wieder, ob die dem Serum zugesetzten Stoffe auch als solche unverändert auf die rothen Blutscheiben zur Wirkung kommen; durch Bestandtheile des Serums könnte ja der schädigende Einfluss des Zusatzes aufgehoben werden oder im Gegentheil erst sich geltend machen. Weiterhin kommt es sehr auf die Menge der Blutscheiben an, auf 
welche die Stoffe einwirken. Das Erkennen des Eintritts vom Lackfarbenwerden von Blut ist nur bei dünnen Blutschichten leicht und sicher; in selbst kleinen Eprouvetten, also Schichten von über $1 / 2 \mathrm{~cm}$ lässt sich der Uebergang von Deckfarbe in Lackfarbe nicht scharf abgrenzen. Nach vielen Versuchen wurde schliesslich das folgende Verfahren als praktisch und zweckmässig angewandt und erprobt.

Ein bis zwei Tropfen Blut wurden mit 5 cem einer indifferenten Flüssigkeit geschüttelt. In dieser Verdünnung (ein Tropfen Blut $=0,05 \mathrm{ccm})$ 5:500 kann der Einfluss des Serums als nahezu ausgeschaltet angesehen werden. Dem gaben Versuche Recht, welche statt mit Blut nur mit Blutkörperchen angestellt wurden, die durch Centrifugiren rom Serum getrennt worden waren. In einigen anderen Versuchen wurden mehrmals mit der betreffenden indifferenten Lösung "gewaschene" Blutscheiben verwendet; diese Versuche hatten das gleiche Resultat wie die mit Verwendung von frischen Blutstropfen. (Gleichgültig in allen Fällen ist es aber nicht, ob „gewaschene" Blutkörperchen oder frisches Blut zu den Versuchen verwendet werden; das zeigte sich bei Versuchen mit Säuren. Es ist desshalb bei Wiederholung der Versuche vorher festzustellen, ob die geringen Serum- resp. Plasmamengen von Einfluss sind oder nicht.) Vortheilhaft zeigte sich dieser Grad der Verdünnung noch dadurch, dass durch die ein bis zwei Tropfen die Flüssigkeit gerade so roth gefärbt war, dass sie, gegen mattweisses Licht gehalten, ein intensives Roth zeigte, welches als Deckfarbe eine Schrift vollkommen verdeckte, die aber, sobald der Umschlag in Lackfarbe erfolgte, durch das Roth jetzt deutlich erkannt werden konnte. Etwaige Verunreinigungen des Blutes, wie kleine und kleinste Gerinnsel, werden in dieser Verdünnung sofort erkannt, ebenso irgend welche Erscheinungen, welche in Folge des zugesetzten Stoffes neben dem Lackfarbenwerden eintreten, z. B. eine Trübung durch Coagula, eine Flockenbildung der rothen Blutscheiben oder dergl.

Da es uns bei den nunmehrigen Versuchen darauf ankommt, Stoffe zu finden, welche durch chemische Einwirkung die "Wand" der rothen Blutscheiben zerstören, so muss bei denselben jede mechanische Zerstörung derselben vermieden werden; eine Schädigung, wie sie durch das Wasser erfolgt, muss absolut ausgeschlossen sein. Dies kann dadurch erreicht werden, dass die Blutkörperchen in einer Lösung suspendirt werden, welche nicht allein ehemisch sich vollkommen indifferent verhält gegen die rothen Blutzellen, sondern 
auch das Volumen derselben nicht oder nicht erbeblich alterirt. Es sind dies $0,9 \%$ ige $\mathrm{NaCl}$-Lösung, $1,42 \% \mathrm{Na}_{2} \mathrm{SO}_{4}, 1,85 \% \mathrm{~K}_{2} \mathrm{SO}_{4}$, $5,5 \% \mathrm{MgSO}_{4}, 9,4 \%$ ige Rohrzuckerlösung und andere. Man sollte meinen, dass über diese Thatsachen schon lange kein Zweifel mehr besteht, gleichwohl ist in Bunge's Lehrbuch der Physiologie, Ausgabe 1901, Bd. II S. 245, folgender Passus zu lesen:

„Denn sobald die rothen Blutkörperchen mit Wasser in Berührung kommen, diffundirt der rothe Blutfarbstoff, das Hämoglobin, welches ihren Hauptbestandtheil bildet, in die Zwischenflüssigkeit, und es bleiben von den Blutzellen nur die sogenannten ,Stromata', verkleinerte, blasse, runde, sehr schwach lichtbrechende, specifisch lejchte Reste übrig.

Wendet man statt des Wassers eine verdünnte Salzlösung von bestimmter Concentration an - z. B. eine Kochsalzlösung von $1 \frac{1 / 2}{\text { bis }} 3 \%{ }^{1}$ ) -, so tritt keine mikroskopisch sichtbare Veränderung der Blutkörperchen ein. In concentrirteren Salzlösungen schrumpfen sie, in verdünnteren quellen sie und geben Hämoglobin an dieselben $a b . "$

Die Rohrzuckerlösungen schwanken in ihrem Gehalt etwas je nach der"Herkunft des Zuckers, die von mir verwendete 9,4\%ige Lösung (94 g Zucker in $1000 \mathrm{ccm}$ Wasser gelöst) hatte eine Gefrierpunktsdepression von $0,577^{\circ} \mathrm{C}$; ; chemisch reiner Rohrzucker von E. Merck, Darmstadt wurde benutzt.

In solchen Lösungen ist der zu prüfende Stoff aufzulösen, und nun sind den versehiedenen Lösungen die Blutscheiben zuzusetzen. Sonst noch $\mathrm{zu}$ beachtende Maassregeln ergaben sich im Verlauf der verschiedenen Versuche und werden dort im Zusammenhang erwähnt.

\section{Einflnss von verschiedenen Giften (Alkaloiden).}

Mehr der Vollständigkeit halber als in Erwartung besonderer Resultate wurden eine Reibe von Alkaloiden in der angegebenen Weise untersucht.

I. In der indifferenten Rohrzuckerlösung wurden gelöst:

Cocain mur. $(5 \%)$, Codeïn phosph. $(2,5 \%)$, Atropin $(0,1 \%)$, Morph. mur. $(2,5 \%)$, Strychnin (gesättigte Lösung), Coffeïn ( $5 \%$ ), Chinin mur., Chinin sulf (gesättigte Lösung). In allen diesen Lösungen sedimentirten die rothen Blutscheiben, und es trat auch nach 24 Stunden noch keine Auflösung ein.

1) Im Original nicht unterstrichen.

E. Pflũger, Arehiv für Physiologie. Bd. 99. 
II. In der indifferenten $\mathrm{Na}_{2} \mathrm{SO}_{4}$-Lösung wurden gelöst:

Cocain mur. $(2,5 \%)$, Codein phosph. $(2,5 \%)$, Atropin $(0,1 \%)$, Morph. mur. $(2,5 \%)$, Strychnin (gesättigte Lösung), Chinin mur., Chinin sulf. (gesättigte Lösungen), Coffeïn (2,5\%).

In allen Lösungen Sedimentation, auch nach 24 Stunden keine Auflösung. (Sobald in den Chininlösungen noch ungelöste Chininkrystalle sich vorfanden, trat deutliches Lackfarbenwerden, also Auflösung der Blutscheiben ein.)

III. In einer indifferenten Lösung von Rohrzucker zu gleichen Theilen mit einer indifferenten Lösung von $\mathrm{NaCl}$ gemischt wurden gelöst:

Cocain mur., Codein phosph., Strychnin nitr., Atropin sulf., Morph. mur.; auch hier kein e Spur von Auflösung nach 24 Stunden.

\section{Einfluss der Wärme.}

Im Laufe meiner Untersuchungen zeigte sich, dass bei sonst gleichen Versuchsbedingungen die Resultate sich doch verschieden gestalteten, je nachdem die Temperatur, bei welcher die Versuche angestellt wurden, variirt wurde. Es war desshalb nöthig festzustellen, inwieweit Temperaturschwankungen, insbesondere Te mperaturerböhungen für sich allein schädigend auf die rothen Blutscheiben einwirken, eventuell sogar für sich allein ein Lackfarbenwerden des Blutes ohne sonstige Nebenerscheinung Eiweissausfällung, Hb-Zersetzung oder dergl. hervorrufen können. Aus der schon bekannten Thatsache, dass durch Erwärmen das Blut lackfarben wird, also rothe Blutscheiben im Serum suspendirt sich auflösen, konnte nicht ohne Weiteres gefolgert werden, dass auch in irgend einer indifferenten Lösung suspendirte Blutscheiben durch Erwärmen lackfarben werden. Jedenfalls wurde ich erst nach vielen anderen Versuchen auf diesen Factor aufmerksam und begann dann systematische Untersuchungen nach dieser Richtung hin, die ich vor den anderen anführe, wenn sie theilweise auch erst nach den anderen angestellt wurden.

Die Versuchsanordnung war die schon beschriebene: stets gleiche Menge Blut in gleichen Mengen Flüssigkeit. Die Untersuchung erfolgte in kleinen Reagenzgläschen alle gleich lang $(9 \mathrm{~cm})$, gleich weit $(13 \mathrm{~mm}$ lichte Weite), so dass $4 \mathrm{ccm}$ Flüssigkeit die Gläschen nicht halb füllt, und ein auch dickes Thermometer beim Eintauchen die Flüssigkeit nicht zum Ueberlaufen bringt. Als Wärmbad dierten 
$8-10 \mathrm{~cm}$ hohe Präparatencylinder, von denen $3-4$ nebeneinander aufgestellt und mit Wasser verschiedener Temperatur dreiviertel gefüllt waren. Ein Thermometer zeigte die Temperatur des Wasserbades, ein zweites befand sich in dem Reagenzgläschen in der Lösung mit den rothen Blutscheiben. Zuerst kam das Reagenzglas mit der Blutprobe in das Bad von niedrigster Temperatur je nach den Vorversuchsergebnissen von $+8^{\circ} \mathrm{C}$. bei wenigen Versuchen, bei andern sogleich von ca. $30^{\circ} \mathrm{C}$. Sobald die Temperatur der Blutprobe die des Wasserbades annähernd erreicht hatte, wurde das Reagenzglas in das nächste Wasserbad getaucht, das $5-8^{\circ} \mathrm{C}$. höhere Temperatur zeigte; trat in diesem Bad noch keine Verfärbung ein, so kam das Reagenzglas in's nächste Bad mit wieder höherer Temperatur u. s. f. Zuweilen wurde auch einfach durch allmähliches $\mathrm{Zugiessen} \mathrm{von}$ heissem Wasser die Temperatur des Wasserbades erhöht, bis der Wechsel von Deckfarbe in Lackfarbe eintrat. Die Temperatur, bei welcher der Umschlag erfolgte, wurde natürlich am Thermometer, welches in dem Blutgemisch sich befand, abgelesen, nicht in dem Wasserbade gemessen. Der Umschlag ist ein scharfer und deutlicher, meistens ist es, als wenn ein Schleier von dem Glase weggezogen würde, und die Flüssigkeit wird durchsichtig, so dass jetzt die Zahlen und Striche des Thermometers, das an die hintere Reagenzglaswand angelehnt und also von einer rothen Flüssigkeitsschicht verdeckt ist, nun deutlich und scharf sichtbar und lesbar werden. Halten der Probe gegen eine helle weisse Fläche und Vergleichen mit noch deckfarbenen und deutlich lackfarbenen Proben erleichtert (auch in zweifelhaften Fällen, die selten sind) die Beobachtung erheblich.

Die Untersuchungsresultate sind folgende: Blut wurde lackfarben in:

1. Rohrzuckerlösung $(9,4 \%)$ bei $62,0^{\circ}-68,0^{\circ} \mathrm{C}$.

2. $\mathrm{MgSO}_{4}(5,5 \%)$-Lösung " $67,0^{\circ}$ "

3. $\mathrm{Na}_{2} \mathrm{SO}_{4}(1,42 \%)$ " $68,0^{\circ}$ "

4. $\mathrm{NaCl}(0,9) \quad " \quad$ " $68,0^{\circ}$ "

5. $\operatorname{NaBr}(1,45) \quad " \quad$ " $68,5^{\circ} n$

6. $\operatorname{KBr}(1,75) \quad " 65,5^{\circ} n$

Prüfung des Einflusses der Concentration der Mischflüssigkeit. Blut wurde lackfarben in:

1. $\mathrm{MgSO}_{4}$-Lösung

$5 \% \quad 6 \% \quad 7 \% \quad 7,5 \%$

$69^{\circ} \mathrm{C} .69^{\circ} \mathrm{C} .68^{\circ} \mathrm{C} .70^{\circ} \mathrm{C}$. 
2. $\mathrm{K}_{2} \mathrm{SO}_{4}$-Lösung

$$
\begin{aligned}
& 1,3 \% \quad 1,75 \% \quad 2,6 \% \\
& 66 \% \text { C. } 65 \% \text { C. } 67 \% \text { C. }
\end{aligned}
$$

3. NaCl-Lösung $\left\{\begin{array}{ccccc}3 \% & 1 \% & 0,9 \% & 0,75 \% & 0,6 \% \\ 69^{\circ} \mathrm{C} . & 69-70^{\circ} \mathrm{C} .69-70^{\circ} \mathrm{C} . & 68-69^{\circ} \mathrm{C} .69^{\circ} \mathrm{C} .\end{array}\right.$

In den meisten Fällen finden wir demnach, dass ein $\mathrm{Er}$ wärmen über $65-68^{\circ}$ Auflösung der rothen Blutscheiben zur Folge hat. Die Temperatur, bei welcher die rothen Blutscheiben durch Erwärmen lackfarben werden, dürfte passend der „Schmelzpunkt" derselben genannt werden.

Wie verhält sich der "Schmelzpunkt" der rothen Blutscheiben im Serum.

M. Schultze ${ }^{1}$ ) beschrieb 1865 die Veränderungen der rothen Blutscheiben beim Erwärmen derselben. Bei $52^{0}$ verändern sich die Blutscheiben in charakteristischer Weise durch Theilungen, Abschnürungen $u$. s. w. in mannigfachen Formen, welche dann alle in Kugelform übergehen, bei ungefähr $60^{\circ} \mathrm{C}$. lösen - sich die kleinen und grossen kugeligen Theilstücke auf, d. h. es entsteht eine lackfarbene Lösung von Hämoglobin von bekanntern Aussehen.

Engelmann ${ }^{2}$ ) bestimmte die Temperatur (bei Anwendung warmer Objecttische), bei der die rothen Blutscheiben die von M. Schultze beschriebenen Veränderungen zeigen, zwischen $56-60^{\circ} \mathrm{C}$.

Stewart ${ }^{3}$ ) erzielte Lackfarbenwerden von Blut bei $60-65^{\circ} \mathrm{C}$.

Rollet ${ }^{4}$ ) brachte $16-17 \mathrm{~cm}$ difibrinirtes Schweineblut in einer Eprouvette in ein Wasserbad, welches auf $60-64^{\circ}$ erhalten wurde; bei dieser Temperatur wurde das Blut innerhalb 15-20 Minuten lackfarben.

1 Theil Blut mit 2 Theilen $60 \%$ iger Rohrzuckerlösung wurde nach $15-20$ Minuten bei $60-65^{\circ}$ lackfarbig.

1 Theil Blut mit 2 Theilen 31,58\% \% iger Dextroselösung wird ebenso bei $60-65^{\circ}$ lackig.

Auch Blut mit Kochsalzlösungen gemischt, wird bei $60-65^{\circ}$ lackig; solches "Salzblut", 1 Theil Blut, 2 Theile NaCl-Lösung, $a$ von $3 \%, b$ von $10,257 \%, c$ von $30 \%$ Gehalt, ,wird durch Er-

1) M. Schultze, Ein heizbarer Objecttisch und seine Verwendung bei Untersuchungen des Blutes. Archiv f. mikr. Anatomie Bd. 1 s. 26-31. 1865.

2) Engelmann, Arch. f. mikrosk. Anat. Bd. 4 S. 384.

3) Stewart, Journal of Physiology vol. 24 p. 210.

4) Rollett, Elektrische u. thermische Finwirkungen auf das Blut und die Structur der rothen Blutscheiben. Pflüger's Archiv Bd. 82 S. 239 u. f. 1900. 
wärmen lackfarbig, und zwar geht das stärker gesalzene Blut dem weniger stark gesalzenen Blut immer voraus, so dass letzteres um einige Minuten länger braucht, um ebenso verändert zu sein, wie das erstere".

In eigenen Versuchen, welche mit defibrinirtem $S \mathrm{ch}$ wein eblut angestellt wurden, fand ich, dass bei $65^{\circ}$ oder bei $66^{\circ} \mathrm{C}$. Lackfärbung eintrat.

Das defibrinirte Schweineblut wurde in denselben Reagenzgläschen in einer Menge von $5 \mathrm{ccm}$ im Wärmebad nach und nach immer höheren Temperaturen ausgesetzt, wie es bei den anderen Versuchen geschah. Die Ablesung der Temperatur erfolgte an dem in der Blutprobe steckenden Thermometer, wenn der Farbumschlag erfolgte, d. h. die hellrothe Farbe dunkel wurde und dünne, an der Wand des Reagenzgläschens durch Schiefhalten entstandene Blutschichten Lackfarbe zeigten. Anfangs erscheint die Erkennung dieses Zeitpunktes schwierig, doch bald bekommt man eine gewisse Sicherheit in der Erkennung desselben, und es war überraschend, eine relative Constanz der Temperaturablesungen feststellen zu können; andere Temperatur, als $65^{\circ}$ und $66^{\circ}$, habe ich in den vielen Untersuchungen mit defibrinirtem Schweineblut nicht beobachtet.

Bei Versuchen mit Katzenblut wurden von defibrinirtem Katzenblut 2 Tropfen in $5 \mathrm{ccm}$ vollkommen klarem, ungefärbtem Katzenblutserum suspendirt und erwärmt, bei $68^{\circ}$ trat Lackfärbung ein.

Als "Schmelzpunkt der rothen Blutkörperchen“, das ist die Temperatur, bei welcher die rothen Blutscheiben schmelzen und das Blut resp. die Blutaufschwemmung lackfarben wird, wurde $68^{\circ}$ C. so oft beobachtet, dass ich anfangs geneigt war, den Schmelzpunkt als einen constanten anzusehen. Weitere Untersuchungen, über welche ich gesondert berichten werde, ergaben, dass der Schmelzpunkt der rothen Blutscheiben schwankt, wenn auch in geringen Grenzen und zwar auch bei demselben Individuum.

Bei den Versuchen mit Rohrzuckerlösungen ist noch hervorzuheben, dass nur frisch ber eitete Lösungen zu verwenden sind.

\section{Einfluss von Säuren.}

Eine oberflächliche Prüfung der Wirkung der Säuren auf rothe Blutscheiben ergab eine zerstörende Wirkung derselben selbst in stark verdünnten Lösungen und liess dadurch das allen Säuren gemeinsame Moment, die Wasserstoff-Ionen, als muthmaasslich 
schädliches Agens erkennen. Bei Prüfung mit Acid. muriat. sulfur. - nitric. - chromic. - picrinic. - oxalic. - acetic. boric. - formic. - citric. - tartaric. - ergab sich durchweg eine Braun- resp. Schwarzfärbung und Auflösung der rothen Blutscheiben. Die Unschädlichkeit der Kohlensäure und ebenso der Lösungen saurer Salze, z. B. der Biphosphate von Kalium und Natrium $\left(\mathrm{KH}_{2} \mathrm{PO}_{4}\right.$ und $\left.\mathrm{NaH}_{2} \mathrm{PO}_{4}\right)$ widersprachen dieser Auffassung von der Schädlichkeit der H-Ionen, denn auch in diesen Lösungen wirkten H-Ionen auf rothe Blutscheiben ein, ohne sie zu zerstören. Nicht die H-Ionen an sich, als vielleicht ihre zu starke Concentration, konnte demnach die Ursache der Schädigung sein. Es kam also darauf an, zu erfahren, bis zu welcher Verdünnung eine Säure ihre schädigende Wirkung auf rothe Blutscheiben noch geltend macht.

\section{Versuch.}

$1 \mathrm{ccm}$ gewöhnliche Salzsäure (also mit etwa 0,25\% $\mathrm{HCl}$ ) mit $9 \mathrm{ccm}$ Rohrzuckerlösung als Stanımlösung wurde weiter mit Rohrzuckerlösung verdünnt, so dass jede folgende Lösung die Hälfte Salzsäure der vorhergehenden hatte; die zweite Verdünnung enthielt also die Hälfte der Salzsäure der Stammlösung, die nächste $1 / 4,1 / 8$ u. s. w. Die ersten 7 Verdünnungen $1 / 2,1 / 4,1 / 8,1 / 16,1 / 32,1 / 64,1 / 128$, bewirkten sofort Lackfarben- und Braunwerden des zugesetzten Blutes, Bei der achten Lösung $1 / 256$ und neunten $1 / 512$ blieb das Blut noch roth und deckfarben, doch nach 1/2 Stunde war es braun und sedimentirte, nach 24 Stunden vollkommene Lackfärbung und Bräunung, die zehnte und elfte Verdünnung 1/1024 und 1/2048 war oǹne Schädigung für die rothen Blutscheiben, das Blut blieb roth, es trat kein Lackfarbenwerden ein, nach 24 Stunden waren die Körperchen roth sedimentirt, die überstehende Flüssigkeit klar farblos.

Die achte Verdünnung 1/256 färbte Congopapier noch blau, die neunte 1/512 gab mit Congopapier keine deutliche Reaction mehr, auf Lackmus reagirte auch Verdünnung elf $1 / 2048$ noch stark. Sämmtliche Lösungen neunter bis elfter Verdünnung, welchedie rothen Blutscheiben nichtschädigten, waren durch das Blut nicht neutralisirt, sondern reagirten, nachdem das Blut sedimentirt war, stark sauer auf Lackmus.

\section{Versuch.}

$0,5 \mathrm{ccm}$ Essig säure mit 9,5 ccm Rohrzackerlösung als Stammlösung wurde mit Rohrzuckerlösung in der gleichen Weise verdünnt wie vorhin und mit Blut beschickt.

nach 24 Stunden

1. Stammlösung ( $1 \mathrm{ccm}$ enthält 0,05 der offic. acid. acet.) macht

Blut sofort lackfarben und braun ......... lackfarben

2. Erste Verdünnung 1/2 (0,025 acid. acet.), nach 1/4 Std. lack-

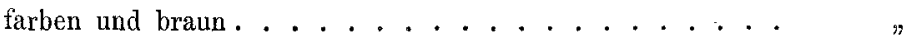

3. Zweite Verdünung $1 / 4$, nach $8 / 4$ Std. lackfarben und braun " 
4. Dritte Verdünnung $1 / 8$, Congo deutliche Reaction nach $4^{3 / 4}$ Std. nach 24 Stunden lackfarben und braun .............

5. Vierte Verdünnung $1 / 16$, Congo undeutlich, nach $4^{3 / 4}$ Std. sedi-

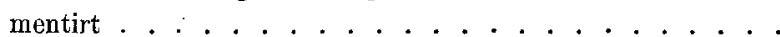

6. Fünfte Verdünnung $1 / 32$, Congo undeutlich, ganz geringe Verfärbung . . . . . . . . . . . . . . . Sediment braun

7. Sechste Verdünnung $1 / 64$, Lackmus stark, nach $4^{3 / 4}$ Std. klar sedimentirt . . . . . . . . . . . ” roth

8. Siebente Verdünnung $1 / 128(0,0003906)$, Lackmus stark, keine

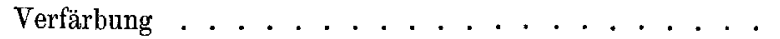

lackfarben

\%

\section{Versuch.}

$20 \mathrm{ccm} \mathrm{Na}_{2} \mathrm{SO}_{4}$-Neutrallösung wurde mit 0 xals äure versetzt, so viel, dass Congopapier deutlich blau wurde. In dieser Stammlösung I wurde Blut sofort braun, aber nicht lackfarben.

In einer Lösung II (2 ccm der Lösung I und $4 \mathrm{ccm}$ Neutrallösung), welche noch deutliche Congoreaction gab, trat Braunfärbung des Blutes nach $5 \mathrm{Min}$. ein.

In einer Lösung III ( $3 \mathrm{ccm}$ II $+3 \mathrm{ccm}$ Neutrallösung), Congoreaction eben noch erkennbar, tritt Braunfärbung des Blutes nach $10 \mathrm{Min}$. ein.

In einer Lösung IV (3 ccm III $+3 \mathrm{ccm}$ Neutrallösung), keine Congoreaction, aber starke Lackmusreaction, verfärbt sich das Blut nicht, bleibt roth deckfarben, sedimentirt, nach 4 Stunden Braunfärbung.

In einer Lösung $V$ (3 ccm IV $+3 \mathrm{ccm}$ Neutrallösung), Lackmusreaction stark, ist noch nach 4 Stunden keine Farbänderung eingetreten.

\section{Versuch.}

Fine $0,5 \%$ ige wässerige Cit r o n en s äure lösung gibt deutliche Congoreaction, in ihr wird Blut sofort braun, die dritte Verdünnung, also eine $0,0625 \%$ ige Citronensäurelösung, gab mit dem benutzten Congopapier keine Reaction mebr, Blut blieb roth.

Diese einer grösseren Versuchsreihe entnommenen Versuche lassen erkennen, dass von den untersuchten Säuren eine Concentration zu finden ist, welche rothe Blutscheiben n i ch t zerstört. Die schädigende Wirkung der Säuren hört allerdings erst bei sehr starken Verdünnungen der Säuren auf, jedoch nicht in Folge von Neutralisation der Säure durch das Blut. In Bezug auf die einzelnen Säuren lässt sich feststellen, dass die Concentration, welche Lackfarbenwerden macht, abhängt von der Natur der Säure, je schwächer die Säure, desto höhere Concentration wird vertragen und umgekehrt. Um Genaueres zu erfahren, reichen natürlich diese Versuche nicht aus, immerhin mussten sie zur Fortsetzung derselben aufmuntern, und vor Allem musste festgestellt werden, ob die beobachteten Reactionen auch constant seien. 
In der Folge stellte sich heraus, dass mancherlei Vorsichtsmaassregeln getroffen werden müssen, um einwandfrei die einzelnen Versuchsresultate mit einander vergleichen zu können. Ich übergehe die vielen $Z$ wischenversuche, welche der Reihe nach Veranlassung zu Abänderungen der Versuchsbedingungen gaben und lehrten, wie Temperatur, Zeitdauer des Versuehs, Concentration der Säure und der Neutrallösung zu berücksichtigen sind. Allmählich gestaltete sich die Versuchsanordnung folgendermaassen:

Neue Versuchsanordnung.

$\mathrm{Zu}$ diesen Versuchen wurden drei viereckige Glaströge mit parallelen Wänden hergerichtet. Die Tröge waren $18 \mathrm{~cm}$ lang, $15 \mathrm{~cm}$ hoch, $4,5 \mathrm{~cm}$ breit und fassten etwas mehr als 11 Wasser, innen war in der Höhe von $10-12 \mathrm{~cm}$ ein Boden aus verzinkten Drahtgeflecht angebracht, auf welchen die Eprouvetten $\mathrm{zu}$ stehen kamen, ein hölzerner durchlochter Deckel diente als Eprouvettenhalter, durch welchen die Eprouvetten neben einander der Nummer nach hineingetaucht wurden. Für Thermometer, Heber zur Wasserentnahme und Trichter zum Nachfüllen sind im Deckel gleichfalls Oeffnungen angebracht.

Alle Eprouvetten enthalten gleich viel Lösung, $4 \mathrm{ccm}$; in jede kommt ein Tropfen $=0,05 \mathrm{ccm}$ defibrinirtes Blut, sofort wird umgeschüttelt, die Zeit notirt und nun auf das Auftreten von dem Wechsel der Deckfarbe in Lackfarbe geachtet. Zuweilen, wenn der Umschlag der einzelnen Proben schnell auf einander erfolgt, ist eine Hülfe sehr am Platze, welche die Zeit abliest und das Protokoll führt.

Die Untersuchungen erfolgten bei den Temperaturen $18^{\circ}, 25^{\circ}$ und $37^{\circ}$. Der Glastrog mit dem $18^{\circ}$ igen Wasser hält seine Temperatur stundenlang ohne Schwankungen. Das Wasserbad von $25^{\circ}$ bedarf nur noch ab und zu eines geringen Zugiessens von wärmeren Wasser, grössere Schwankungen als $1^{0}$ kamen nie vor. Mehr muss man bei dem Wasserbad von $37^{\circ}$ auf die Temperatur achten, da schon innerhalb einer halben Stunde Abfall der Temperatur um $1-2^{\circ}$ erfolgen kann. Abnehmen von Wasser und Zugiessen von warmem Wasser ist öfters nothwendig, wenn man das Glas nicht in einen Thermostaten setzen will, wodurch freilich die Ablesung und Beobachtung erschwert wird; durch Zugiessen des warmen Wassers in eine bis auf den Boden des Glastroges reichende Röbre wird gleich- 
mässige Erwärmung des ganzen Wasserbades erreicht, wie ich durch Einsetzen mehrerer Thermometer in gleicher Höhe feststellte, zwischen oben und unten kam ein Unterschied von höchstens $2-3^{0}$ vor, die Eprouvetten standen im Bad mit Sehwankungen von höchstens $2^{\circ}$.

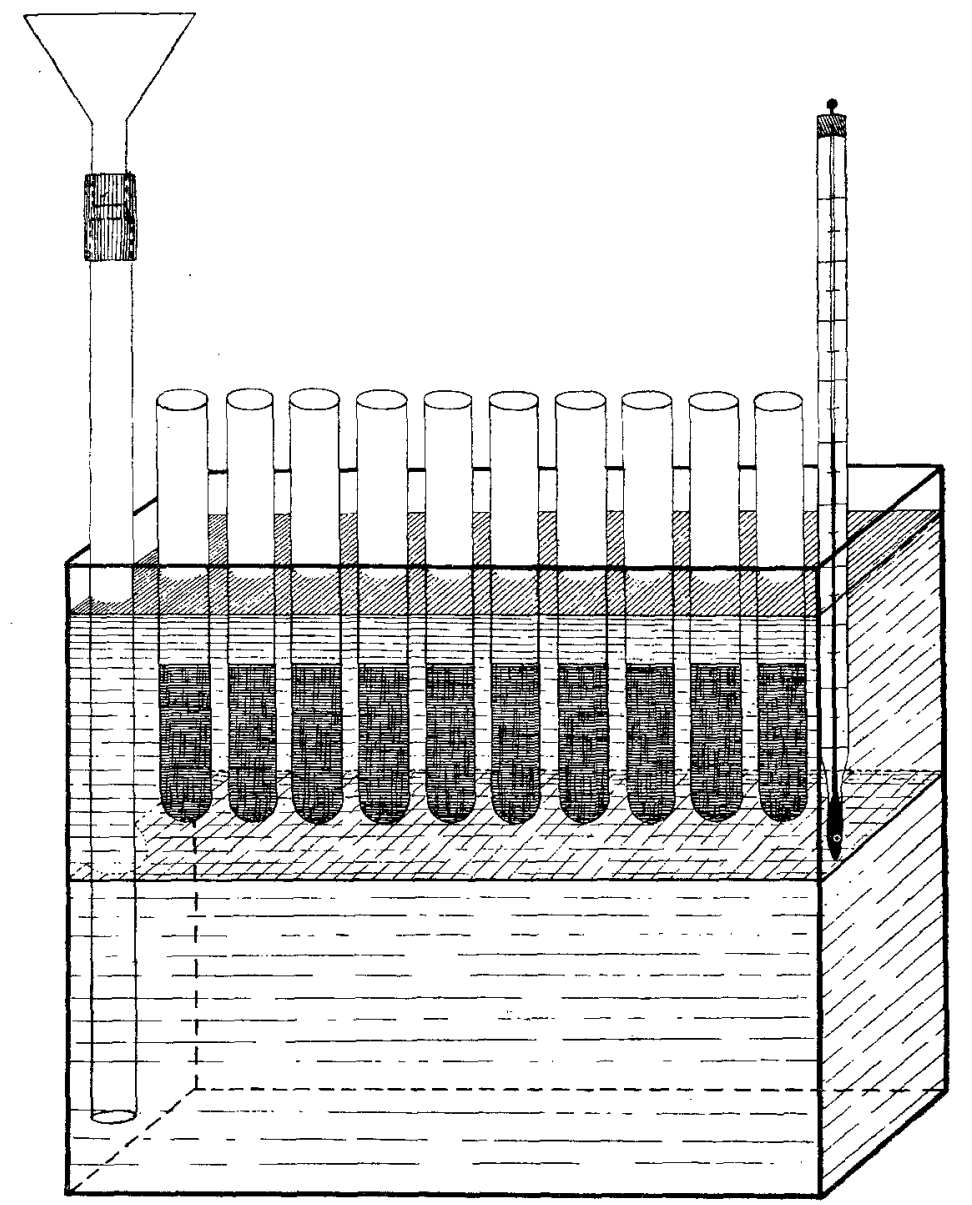

Die drei Glaströge stehen neben einander dem hellen Fenster zugewendet, welches durch einen weissen Schirm eine gleichmässige Helligkeit gibt (besonders ist bei Sonnenlicht der Schirm nothwendig), so dass alle Proben das gleiche Licht erhalten. Die Beobachtung ist eine ungemein scharfe und exacte.

Als Neutrallösung wurde Rohrzuckerlösung verwendet; anfangs die bisher gewohnte $9,4 \%$ ige Lösung, allein bald wurde die 
von doppelter Concentration gewählt. Wenn die 9,4\%ige Rohrzuckerlösung mit z. B. einer $1 / 100 \mathrm{n}$. HCl-Säure zu gleichen Theilen gemischt, und in diese Mischung rothe Blutscheiben versetzt wurden, so kam allerdings die Wirkung von $1 / 200 \mathrm{n}$. HCl-Lösung auf den Blutscheiben zur Beobachtung, jedoch nicht in einer $9,4 \%$ igen Rohrzuckerlösung, sondern in einer $4,7 \%$ igen, also wesentlich schwächeren Lösung, welche keineswegs mehr als Neutrallösung bezeichnet werden kann; zur Säurewirkung gesellt sich in solchen Fällen ein mehr oder weniger grosser Bruchtheil rein physikalischer Wasserwirkung, welche wir ja doch ausgeschaltet wissen wollten. Zur Prüfung verschiedener Säureconcentrationen auf rothe Blutscheiben werden desshalb jetzt erst die verschiedenen Säureconcentrationen hergestellt durch Verdünnen der Säurestammlösung ( $1 / 100$ oder $1 / 10 \mathrm{n}$.) mit Wasser, von diesen verschiedenen wässerigen Concentrationen wurden je $2 \mathrm{cem}$ mit $2 \mathrm{cem} 2 \times 9,4 \%$ iger Rohrzuckerlösung gemischt und auf diese Weise die betr. Säuremenge in einer wirklicben Neutrallösung $(9,4 \%$ Rohrzucker $)$ in ihrer Wirkung auf rothe Blutscheiben geprüft.

Der Gang der Untersuchung gestaltete sich demgemäss wie folgt: Zuerst Herrichtung der 3 Warmbäder zu $18^{\circ}, 25^{\circ}$ und $37^{\circ} \mathrm{C}$.; dann Herstellung der betreffenden Säureverdünnungen aus der Stammlösung

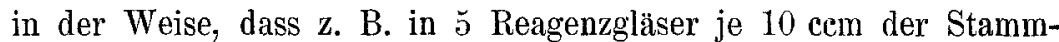
lösung der Säure dazu entsprechend $0,1,2,3,4 \mathrm{ccm}$ Wasser gefüllt wurden, umschütteln; von diesen 5 Concentrationen wurden je 3 Eprouvetten mit 2 ccm beschickt, dazu je 2 cem $2 \times 9,4 \%$ igen Rohrzuckerlösung und nun je 5 Eprouvetten mit den 5 verschiedenen Concentrationen der Säure in das Warmbad gesetzt (vorher wieder umschütteln!). Nachdem die Mischungen die Temperatur des Bades angenommen hatten, wurde in jede Eprouvette 1 Tropfen defibrinirtes Schweineblut eingetropft, aus einer Pipette, welche $1 \mathrm{ccm}$ fasst und welche genau in 20 Tropfen diesen Cubikcentimeter Blut auslaufen liess, so dass demnach jeder Tropfen $0,05 \mathrm{cem}$ Blut enthält. So gestalteten sich die Versuchsbedingungen bei allen Versuchen als fast ganz gleich. Da das Schweineblut sehr schlecht sedimentirt, war das Verhältniss von Blutkörperchen und Serum in jedem Tropfen gleichfalls fast dasselbe; älteres, als 2 Tage altes Blut, wurde nicht benutzt, jedes Mal aber das Blut mit Luft geschüttelt, bis es hellroth war. Zuweilen wurde auch Fingerblut benutzt. Die Menge des Blutes an sich, welche zum Versuch benutzt wird, ist ohne wesentlichen Einfluss; Hauptsache ist, dass jede Eprouvette gleich 
viel Blut bekommt, so dass alle Eprouvetten auf den gleichen Farbenton abgestimmt sind, und durch Vergleichen mit den nebenstehenden Proben der eintretende Umschlag aus Deckfarben in Lackfarben mit grösster Genauigkeit sich beobachten lässt.

Während des Aufenthalts im Bade sind die Blutproben unausgesetzt zu beobachten, um sofort den Farbenumschlag zu erkennen und den Zeitpunkt auf der bereitliegenden Uhr feststellen zu können. Gleichzeitig ist die Temperatur zu controliren. Zieht sich der Versuch in die Länge, so ist genügend Zeit zwischen den einzelnen Ablesungen, um die Temperaturschwankungen zu corrigiren, welche sich leicht auf ${ }^{1 / 2}$ bis höchstens $1^{0}$ einschränken lassen.

\section{Neue Versuche.}

\section{Versuch.}

Stammlösung: $1 / 100 \mathrm{n}$. HCl.

$1 / 100$ n. HCl. . . . . . . . . . . . . . $10 \quad 10 \quad 10 \quad 10 \quad 10 \mathrm{ccm}$

Aq. dest. . . . . . . . . . . . . . 0 o $1 \quad 2 \quad 3 \quad 4$ ccm

Von diesen Verdünnungen werden je $2 \mathrm{~cm}$ mit $2 \mathrm{~cm} 2 \times 9,4 \%$ iger Rohrzuckerlösung gemischt; es enthält demnach

$\begin{array}{lllllllllll}\text { Eprouvette . . . . . } & \text { Nr. } & 1 & 2 & 3 & 4 & 5\end{array}$

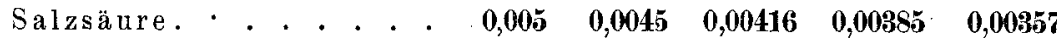

12 h 7 ' erhielt jede Eprouvette 1 Tropfen defribr. Schweineblut. Lackfarbenwerc̉en des Blutes trat ein

im Wasserbad $18-17^{\circ}$ C. $12^{\text {h }} 29^{\prime} \quad 12$ h $31^{\prime} \quad 12^{\text {h }} 34^{\prime} \quad 12$ h $40^{\prime} \quad 12^{\text {h }} 45^{\prime}$ $\begin{array}{lllllll}\text { also nach Minuten . . } & \text {. } & \mathbf{2 2} & \mathbf{2 4} & \mathbf{2 7} & \mathbf{3 3} & \mathbf{3 8}\end{array}$

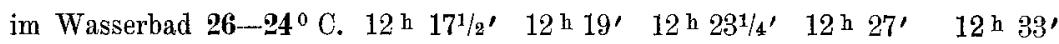

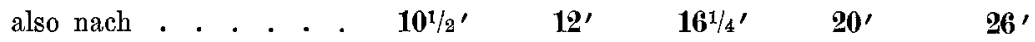
im Wasserbad $38-37^{\circ}$ C. $12^{\text {h }} 11^{\prime} \quad 12^{\text {h }} 12^{\prime} \quad 12^{\text {h }} 13^{\prime} 12^{\mathrm{h}} 13^{1 / 4^{\prime}} \quad 12^{\mathrm{h}} 13^{1 / 2^{\prime}}$ $\begin{array}{lllllll}\text { also nach . . . . . . } & 4^{\prime} & 5^{\prime} & 6^{\prime} & 6^{1 / 4^{\prime}} & 6^{1 / 2^{\prime}}\end{array}$

Im Wasserbad von $18^{\circ}$ war der Uebergang von Deckfarbe zur Lackfarbe sehr scharf und deutlich, die Braunfärbung trat erst einige Zeit später ein; im Wasserbad von $37^{\circ}$ folgte die Braunfärbung dem Umschlag von Deckfarbe in Lackfarbe fast unmittelbar.

Der Eintritt der Reaction wurde von mir beobachtet und durch ein ,jetzt" dem Beobachter der Uhr und Protokollanten angezeigt, welcher die Zeit und die Eprouvettennummer sofort notirte. 


\section{Versuch.}

Stammlösung: 1/100 n. $\mathrm{H}_{2} \mathrm{SO}_{4}$.

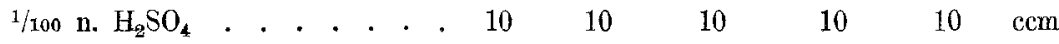
Aq. dest. . . . . . . . . . . $\begin{array}{llllllll}0 & 1 & 2 & 3 & 4 & \mathrm{ccm}\end{array}$

Eprouvette . . . . . Nr. $1 \begin{array}{llllll} & 1 & 2 & 3 & 4 & 5\end{array}$

$\mathrm{H}_{2} \mathrm{SO}_{4}$ n. . . . . . . . . . $0,005 \quad 0,0045 \quad 0,00416 \quad 0,003850,00357$

$1^{\mathrm{h}} \mathbf{1}^{3 / 4^{\prime}}$ erhielt jede Eprouvette 1 Tropfen defribr. Schweineblut. Lackfarbenwerden des Blutes trat ein

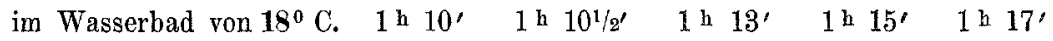
also nach . . . . . . $\quad 8^{1 / 4^{\prime}} \quad 8^{3 / 4^{\prime}} \quad 1^{1 / 4^{\prime}} \quad 1^{1} /_{4^{\prime}} \quad 1^{1 / 4^{\prime}}$

$1^{\text {h }} 3^{\prime}$ Blut zugesetzt

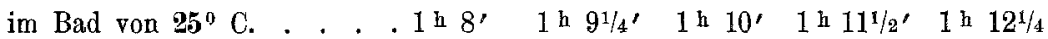

$\begin{array}{lllllll}\text { also nach . . . . . . } 6^{\prime} / 4^{\prime} & 7^{1 / 2^{\prime}} & 8^{1 / 4^{\prime}} & 9^{3 / 4^{\prime}} & 1^{1} / 2^{\prime}\end{array}$

im Bad von $37^{\circ} \mathrm{C}$. . . . . $1^{\text {h }} 5^{\prime} \quad 1^{\text {h } ~} 5^{\prime} \quad 1^{\text {h }} 5^{1 / 4^{\prime}} \quad 1^{\text {h }} 5^{3 / 4^{\prime}} \quad 1^{\text {h }} 6^{\prime}$

$\begin{array}{llllllll}\text { also nach . . . . . . . . } & \mathbf{2} & \mathbf{Q}^{\prime} & \mathbf{2}^{1 / 4^{\prime}} & \mathbf{2}^{3 / 4^{\prime}} & \mathbf{3}^{\prime}\end{array}$

\section{Versuch.}

Stammlösung: $1 / 100 \mathrm{n}$. $\mathrm{H}_{2} \mathrm{SO}_{4}$.

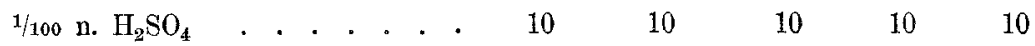

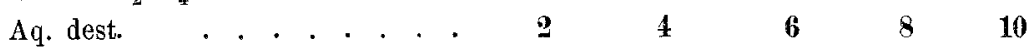

Eprouvette . . . . . . . . Nr. $\quad 1 \quad \begin{array}{llllll} & & 2 & 3 & 4 & 5\end{array}$

$\mathrm{H}_{2} \mathrm{SO}_{4} \quad$. . . . . . . . . . . $0,00416 \quad 0,00357 \quad 0,00312 \quad 0,00278 \quad 0,0025$

$\mathbf{1 1}^{\mathrm{h}} \mathbf{3 6}^{1 / 2^{\prime}}$ Blutzusatz. Lackfarbenwerden des Blutes trat ein im $\mathrm{Bad}$ von $18^{\circ} \mathrm{C}$. . . $11^{\mathrm{h}} 47^{1 / 2^{\prime}} \quad 11^{\mathrm{h}} 54^{\prime} \quad 11^{\mathrm{h}} 58 \mathrm{1}^{\prime} \mathrm{g}^{\prime} \quad 11^{\mathrm{h}} 65^{\prime}$ 1 $11^{\mathrm{h}} 70^{\prime}$ also nach . . . . $\quad 1^{\prime} \quad 1^{\prime} 7^{1 / 2^{\prime}} \quad 22^{\prime} \quad 28^{1 / 2^{\prime}} \quad 33^{1 / 2} 2^{\prime}$

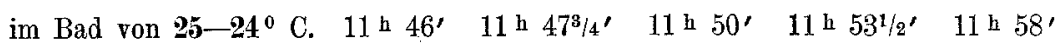

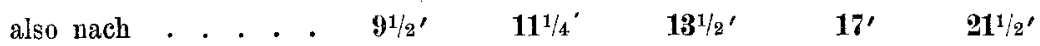

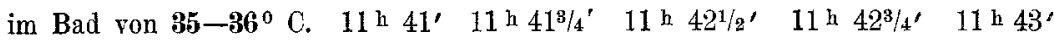
also nach . . . . . $4^{1 / g^{\prime}} \quad 5^{1 / 4^{\prime}} \quad 6^{\prime} \quad 6^{1 / 4^{\prime}} \quad 6^{1 / 2^{\prime}}$

In gleichzeitig aufgestellter HCl-Lösung von 0,005 n. Concentration wurde dasselbe Blut im Bad von $18^{\circ}$ nach $\mathbf{2 0}$ lackfarben.

\section{Versuch.}

Stammlösung $1 / 10 \mathrm{n}$. Acid. formicicum.

$1 / 10$ n. Ameisensäure . . . . . . $10 \quad \begin{array}{llllll}10 & 10 & 10 & 10 & 10 & \mathrm{ccm}\end{array}$ Aq. dest. ........... $0 \begin{array}{lllllll} & 0 & 1 & 2 & 3 & 4 & \mathrm{ccm}\end{array}$

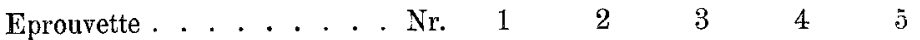
Acid. form. n. . . . . . . . $0,05 \quad 0,045 \quad 0,0416 \quad 0,0385 \quad 0,0357$

$12^{\mathrm{h}} \mathbf{3 4}^{1 / 2^{\prime}}$. Zusatz von 1 Tropfen Schwe ineblut. Lackfarbenwerden des Blutes im Bad von $18^{\circ}$ C. . . . . $12^{\mathrm{h}} 37^{1 / 2^{\prime}} \quad 12^{\mathrm{h}} 39^{\prime} \quad 12^{\mathrm{h}} 40^{\prime} \quad 12^{\mathrm{h}} 42^{\prime} \quad 12^{\mathrm{h}} 44^{\prime}$ also nach. ..... $\quad 3^{\prime} \quad \mathbf{4}^{1 / 2^{\prime}} \quad \tilde{5}^{1 / 2^{\prime}} \quad 7^{1 / 2^{\prime}} \quad 9^{1 / 2^{\prime}}$ 
hei $25^{\circ}$ C. . . . . . $12 \mathrm{~h} 37^{1 / 2^{\prime}} \quad 12^{\mathrm{h}} 38^{1 / 2^{\prime}} \quad 12^{\mathrm{h}} 39^{1 / 4^{\prime}} \quad 12^{\mathrm{h}} 39^{1 / 2^{\prime}} \quad 12^{\mathrm{h}} 399^{1 / 2^{\prime}}$ also nach. . . . . $\quad 3^{\prime} \quad 4^{\prime} \quad 4^{3 / 4^{\prime}} \quad 5^{\prime} \quad 5^{\prime}$

bei $37^{\circ} \mathrm{C}$. werden alle innerhalb 2 Minuten gleichzeitig braun.

\section{Versuch.}

Stammlösung $1 / 10 \mathrm{n}$. Acid. formicicum.

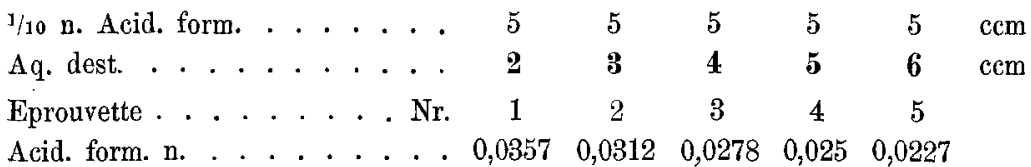

$1^{\text {h }} 1^{\prime}$ Zusatz von Fing erblut; wird lackfarben bei $18^{\circ}$ C. . . . . . . . . $1^{\text {h }} 4^{\prime} 1^{\text {h }} 4^{3 / 4^{\prime}} 1^{\text {h }} 6^{\prime} 1^{\text {h }} 7^{\prime} 1^{\text {h }} 8^{1 / 2^{\prime}}$ also nach ........... . . 3' $3^{3} / 4^{\prime} \quad 5^{\prime} \quad 6^{\prime} \quad 7^{\prime}$

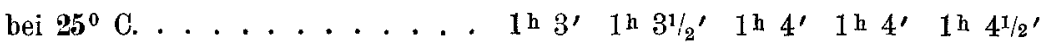
also nach ........... . . $1^{\prime} \quad 1^{1 / 2^{\prime}} \quad \mathbf{2}^{\prime} \quad \mathbf{2}^{\prime} \quad \mathbf{2}^{1 / 2^{\prime}}$ bei $37^{\circ} \mathrm{C}$. werden alle s ofort, Nr. 5 in 1 Minute lackfarben.

\section{Versuch.}

Stammlösung $1 / 10$ n. Acidum aceticum.

$1 / 10$ n. Acid. acet. . . . . . . . $10 \quad 10 \quad 10 \quad 10 \quad 10 \quad$ ccm Aq. dest.. . . . . . . . . $4 \begin{array}{llllll}4 & 8 & 12 & 16 & 20 & \text { ccm }\end{array}$

Eprouvette . . . . . . Nr. $1 \quad \begin{array}{llllll} & 1 & 2 & 3 & 4 & 5\end{array}$

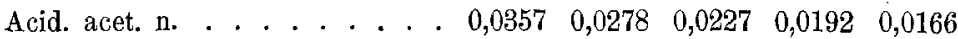

19h 45'. Zusatz von 1 Tropfen Schweineblut; wird lackfarben bei $37^{\circ}$ C. . . . . . . . . . . 1h $2^{\prime} 1^{\text {h }} 8^{\prime}$ ih $10^{\prime} 1^{\text {h }} 11^{\prime}$ ih $12^{\prime}$ also nach .......... 16' $\quad \mathbf{2 3}^{\prime} \quad \mathbf{2 5}^{\prime} \quad \mathbf{2 6}^{\prime} \quad \mathbf{2 7 ^ { \prime }}$ bei $25^{\circ} \mathrm{C}$. wird Nr. $11^{\mathrm{h}} 30^{\prime}$, also nach 45 Minuten, lackfarben; bei $18^{\circ} \mathrm{C}$. wurde der Umschlag nicht abgewartet. Der Umschlag war, ausser bei den Verdünnungen 1 und 2, bei $87^{\circ}$ nicht scharf; die Daten beziehen sich auf den Beginn der Reaction, welche ziemlich lange dauert bis sie vollendet, d. h. vollkommene Lackfarbe da ist (bis 30 Minuten).

\section{Versuch.}

Stammlösung 1/10 n. Acidum aceticum.

$1 / 10$ n. Acid. acet. . . . . . . . . . $10 \quad 10 \quad 10 \quad 10 \quad 10 \mathrm{ccm}$

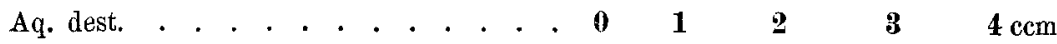

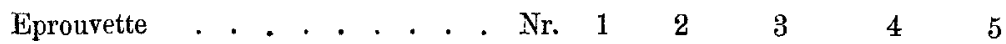
Acid. acet. n. . . . . . . . . . . $0,05 \quad 0,045 \quad 0,0416 \quad 0,03850,0357$

$1^{\mathrm{h}} 5^{1 / 2}$ ' Zusatz von 1 Tropfen Schweineblut, wird lackfarben bei $35-37^{\circ}$ C. . . . . . 1h $24^{\prime} \quad 1^{\text {h } 26^{\prime}} 1^{\text {h }} 28^{\prime} \quad 1^{\text {h }} 28^{1 / 2} 2^{\prime} \quad 1$ h $2 g^{\prime}$ also nach . . . . . . . 18 $\mathbf{1 8}^{1 / 2^{\prime}} \quad \mathbf{2 0}^{1 / 2^{\prime}} \quad 22^{1 / 2^{\prime}} \quad \mathbf{2 3}^{\prime} \quad 28^{1 / 2^{\prime}}$

Gleichzeitig mit demselben Blut beschickte 0,005 n. HCl-Mischung wurde nach $19^{1 / 2^{\prime}}$ lackfarben bei $18^{\circ} \mathrm{C}$. 


\section{Versuch.}

In Mischungen von:

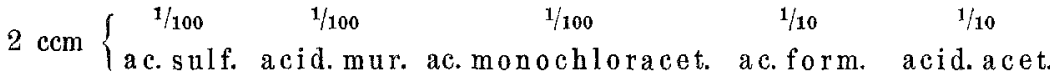
$2 \mathrm{ccm} 2 \times 9,4 \%$ iger Rohrzuckerlösung.

$\begin{array}{ccccc}\text { Eprouvette Nr. } & 1 & 2 & 3 & 4 \\ \mathbf{5} \text { h } \mathbf{9}^{\prime} & \text { Zusatz von } & \mathbf{1} & \text { Tropfen } & \text { Schweineblut, wird lackfarben }\end{array}$

\begin{tabular}{|c|c|c|c|c|c|c|c|}
\hline $\begin{array}{l}\text { bei } 18^{\circ} \mathrm{C} \text {. } \\
\text { also nach }\end{array}$ & $\cdot \cdot$ & .. & $\begin{array}{c}5 \text { h } 17^{\prime} \\
8^{\prime}\end{array}$ & $\begin{array}{c}5 \mathrm{~h} 22^{\prime} \\
\mathbf{1 3}^{\prime}\end{array}$ & $\begin{array}{c}5 \text { h } 23^{\prime} \\
14^{\prime}\end{array}$ & $\begin{array}{c}5 \text { h } 11^{\prime} \\
2^{\prime}\end{array}$ & - \\
\hline ei $25-23^{\circ}$ & C. . & . & $5 \mathrm{~h} 15^{\prime}$ & 5 h $19^{\prime}$ & 5 h $20^{\prime}$ & 5 b $10^{\prime}$ & - \\
\hline & 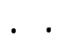 & & $6^{\prime}$ & $10^{\prime}$ & $11^{\prime}$ & $\mathbf{1}^{\prime}$ & - \\
\hline$-35^{0}$ & C. . & . & $\begin{array}{c}5^{h}+12^{1 / 2^{\prime}} \\
3^{1 / 2^{\prime}}\end{array}$ & $\begin{array}{c}5 \text { h } 13^{1 / 2^{\prime}} \\
41 / 2^{\prime}\end{array}$ & $\begin{array}{c}5^{\text {h }} 14^{\prime} \\
5^{\prime}\end{array}$ & $\begin{array}{c}5 \text { h } 9^{1 / 2^{\prime}} \\
1 / 2^{\prime}\end{array}$ & $\begin{array}{c}7 \text { h } 25^{\prime} \\
16^{\prime}\end{array}$ \\
\hline
\end{tabular}

13. Versuch.

In Mischungen von:

$2 \mathrm{ccm} \quad 1 / 100 \quad 1 / 100 \quad 1 / 100 \quad 1 / 10 \quad 1 / 10$

n. acid.: sulf. bydrochl. monochloracetic. formic. acetic.

$2 \mathrm{ccm} 2 \times 9,4 \%$ ige Rohrzuckerlösung.

$\begin{array}{llllll}\text { Eprouvette Nr. } & 1 & 2 & 3 & 4 & 5\end{array}$

12 h 4' Zusatz von 2 Tropfen Fingerblut; wird lackfarben

bei $18^{\circ} \mathrm{C}$. . . $12^{\mathrm{h}} 8^{\prime} \quad 12^{\mathrm{h}} 9^{\prime} \quad 12^{\mathrm{h}} 14^{\prime} \quad 12^{\mathrm{h}} 5^{\prime} \quad 1 \mathrm{~h} 15^{\prime}$

also nach . . . . $\quad 4^{\prime} \quad 5^{\prime} \quad 1^{\prime} \quad 1^{\prime}$ über 70'

12 h $5^{\prime}$ Blutzusatz, wird lackfarben

bei $25^{0}$ C. . . . 12 h $81_{2^{\prime}}^{\prime} \quad 12^{\mathrm{h}} 8^{1 / 2^{\prime}} \quad 12^{\mathrm{h}} 12^{1 / 2^{\prime}} \quad 12^{\mathrm{h}} 6^{\prime} \quad 12^{\text {h }} 50^{\circ}$

also nach . . . . $\begin{array}{lllll}3^{1} / 2^{\prime} & \mathbf{3}^{1 / 2^{\prime}} & 7^{1} / 2^{\prime} & 1^{\prime} & \text { über 45 }\end{array}$

12 h 6' Blutzusatz, wird lackfarben

bei $37^{\circ} \mathrm{C}$. . . $12^{\mathrm{h}} 8^{\prime} \quad 12^{\mathrm{h}} 9^{\prime} \quad 12^{\mathrm{h}} 9^{\prime} \quad 12^{\mathrm{h}} 6^{1 / 9^{\prime}} 12^{\mathrm{h}} 19^{\prime}$

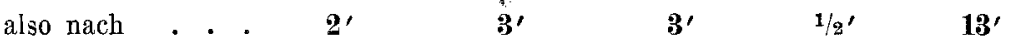

Anmerkung: Fingerblut tropft nicht so schnell, wenn der Stich in den Finger nicht tief ist, desshalb wurde jede Serie Eprouvetten mit besonderer Zeitangabe versehen. (Bei Schweineblut braucht das Eintropfen in alle 15 Eprouvetten noch nicht $3 / 4$ Minute Zeit.

\section{Versuch.}

$1 / 100$ n. $\mathrm{H}_{2} \mathrm{SO}_{4} \quad$. . . . . . . . . $20 \quad 20 \quad 20 \quad 20 \quad 20 \quad 20 \mathrm{ccm}$ Aq. dest. , . . . . . . . . . $\quad 0 \quad 5 \quad 50 \quad 30 \quad 60 \mathrm{ccm}$

Hiervon zu gleichen Theilen mit $2 \times 9,4 \%$ iger Rohrzuckeriösung gemischt enthält

Pipette . . . . . . . . . . . . Nr. $11 \quad 2 \quad \begin{array}{lllll} & 1 & 2 & 4 & 5\end{array}$

g-mol $\mathrm{H}_{2} \mathrm{SO}_{4}$ in $9,4 \%$ iger Rohrzuckerlösung. $0,005 \quad 0,004 \quad 0,0025 \quad 0,002 \quad 0,00125$

4 h $40^{\prime}$ Zusatz von 2 Tropfen defibrinirten Schweineblut; Lackfarbenwerden trat ein 


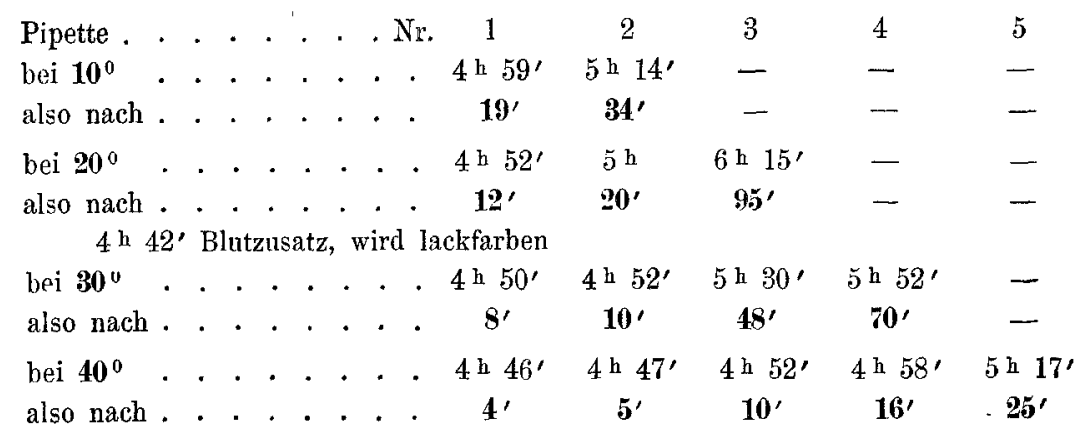

Am nächsten Tage waren die Blutproben in Eprouvette 5 (ausser die bei $40^{\circ}$ ) alle roth, nicht lackfarben; die überstehende Flüssigkeit reagirte we nig er sauer als vor dem Blutzusatz.

Besprechung der Versuche mit Säuren.

Die Vorversuche mit Säuren ergaben, dass die rothen Blutscheiben durch Säuren erst bei einer gewissen Concentration derselben geschädigt werden, also die rothen Blutscheiben eine gewisse Toleranz gegen Säuren haben. Von schwachen Säuren werden stärkere Lösungen vertragen als von starken. Dieses Verhalten zeigt sich in den übrigen Versuchen bestätigt, wird aber durch weitere Beobachtungen ergänzt.

Das Eintreten des Lackfarbenwerden rother Blutscheiben bei Finwirkung von Säuren auf dieselben erscheint als ein vollkommen gesetzmässiges: Das Lackfarbenwerden wird beeinflusst durch

1. die Natur der verwendeten Säure,

2. die Concentration der Säure,

3. die Temperatur,

4. die Zeit.

1. Die Natur der verwendeten Säure macht ihren Einfluss geltend derart, dass

a) bei gleicher Temperatur und gleicher Concentration (Normalgehalt) der Eintritt der Reaction um so eher erfolgt, je stärker die Säure ist und

b) bei gleicher Temperatur erfolgt die Reaction zur gleichen Zeit in schwachen Lösungen starker Säuren und starken Lösungen schwacher Säuren.

Ordnen wir die Säuren nach dem Grade ihrer Einwirkung, so finden wir am stärksten blutkörperchenzerstörend die Schwefelsäure, dann Salzsäure, Monochloressigsäure, Ameisensäure und zuletzt Essig- 
säure. Diese Reihenfolge ist aber die gleiche, wie sich diese Säuren in Bezug auf ihre elektrolytische Dissociation verhalten; Schwefel- und Salzsäure dissociiren am stärksten, Essigsäure am schwächsten. Dieses Verhalten lässt vermuthen, dass die W irkung der Säuren auf rothe Blutscheiben identiseh ist mit einer specifischen Wirkung der freien Wasserstoff-Ionen. Die freien Wasserstoff-Ionen sind allen wässerigen Lösungen von Säuren gemeinsam, die Menge der H-Ionen in denselben hängt davon $a b$, wie stark die betreffende Säure dissociirt. In geringen Concentrationen starker Säuren finden sich im gleichen Volumen in Folge der starken Dissociation eben so viel H-Ionen wie in starken Concentrationen schwacher Säuren. Eine Proportionalität zwischen Menge der freien H-Ionen und Geschwindigkeit des Eintritts des Lackfarbenwerdens ergaben die Versuche jedenfalls. Es ist noch festzustellen, ob diese Proportionalität sich zahlenmässig genau oder nur annäherungsweise ergibt. (Weitere Untersuchungen sind im Gange und werden später veröffentlicht werden.)

2. Die Concentration der Säure. Bei Verwendung verschiedener Concentrationen derselben Säure ergibt sich:

a) bei gleicher Temperatur ist der Eintritt der Reaction abhängig von der Concentration: die Reactionsgeschwindigkeit wächst mit der Concentration.

b) bei gleicher Concentration ist der Eintritt der Reaction abhängig von der Temperatur: die Reactionsgeschwindigkeit wächst mit der Erhöhung der Temperatur.

Eine einfache Proportionalität zwischen Concentration und Geschwindigkeit des Eintritts der Reaction scheint nicht zu bestehen. Vielmehr wächst die Geschwindigkeit viel schneller als der Concentration entspricht, aber bei verschiedener Temperatur auch verschieden schnell. Vergleichen wir die beiden $\mathrm{H}_{2} \mathrm{SO}_{4}$-Versuche, so finden wir

bei $18^{\circ}$ Eintritt der Reaction in $8^{1 / 4}$ Min. bei 0,005 Concentr.,

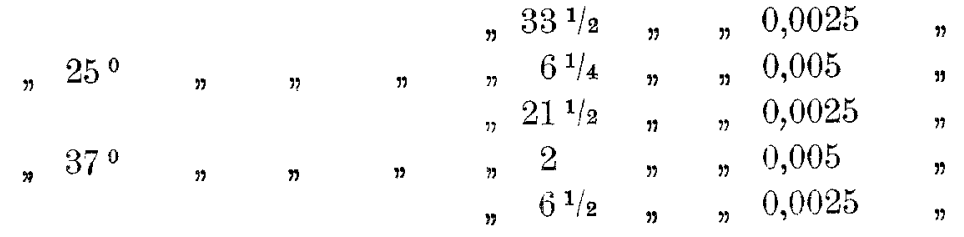


also bei $18^{\circ}$ bei doppelter Concentration in ${ }^{1 / 4} \quad 0,25 \%$ der Zeit

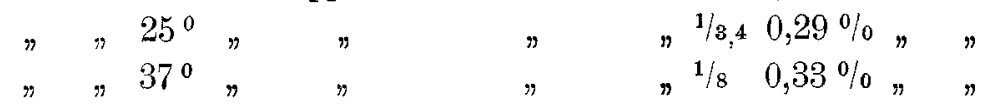

Auch zwischen Temperaturanstieg und Eintritt der Reaction besteht keine Proportionalität. Mit steigender Temperatur nimmt die Reactionsgeschwindigkeit zu, aber mit Beschleunigung.

Einfachere Zahlen, welche sich leichter übersehen lassen, ergibt der Versuch Nr. 14.

Die in Versuch 14 verwendeten Concentrationen sind so geringe, dass in ihnen eine vollständige Dissociation angenommen werden kann, und desshalb wird der Gehalt an H-Ionen zweier Lösungen sich fast wie die Concentrationen verhalten. $\mathrm{Z}$ wei $\mathrm{H}_{2} \mathrm{SO}_{4}$-Lösungen, deren Concentrationen sich wie 1 zu 2 verhalten, werden auch annähernd eine Concentration an H-Ionen im Verhältniss 1:2 haben.

In diesem Versuch 14 baben wir nun 3 Paare von $\mathrm{H}_{2} \mathrm{SO}_{4}$-Lösungen, deren Concentrationen sich wie 2:1 verhalten, und deren Gehalt an H-Ionen demnach gleichfalls annähernd gleich $2: 1$ zu setzen ist.

Wir finden nun, dass bei doppeltem Gehalt an H-Ionen die Reaction nicht in der Hälfte der Zeit, sondern eher eintritt; die Geschwindigkeit des Reactionseintritts ist also der Zahl der Wasserstoffionen nicht proportional.

Die drei Concentrationspare sind 1. und 3., 2. und 4., 3. und 5.; die bei diesen gefundenen Reactionszeiten bei $40^{\circ}$ sind 4 und 10 , 5 und 16, sowie 10 und 25 Minuten; also bei halber Concentration Eintritt der Reaction nach $\mathrm{mehr}$ als doppelter Zeit. Bei geringerer Temperatur sind die Unterschiede noch grösser: bei $30^{\circ}$ tritt die Reaction bei halber Concentration erst nach der sechsfachen und siebenfachen Zeit ein, bei $20^{\circ}$ erst nach achtfacher Zeit.

Dass in der 5. Concentration: $0,00125 \mathrm{H}_{2} \mathrm{SO}_{4}$ bei $30^{\circ}$ und bei niedriger Temperatur auch in noch stärkeren Concentrationen das Lackfarbenwerden überhaupt nicht eintritt, während diese Concentration bei $40^{\circ}$ genügt, Lackfarbenwerden zu bewirken, und in diesen Concentrationen nach Zusatz des Blutes eine deutliche Abschwächung der sauren Reaction festzustellen ist, beweist, dass H-Ionen verschwunden sind, was ja ohne Weiteres zu erwarten ist, da doch durch das alkalische Blut eine gewisse Zahl H-Ionen neutralisirt werden. Trotz des geringen Blutzusatzes macht sich doch diese E. Pflüger. Archiv für Physiologie. Bd. 99. 
Neutralisation geltend, am stärksten natürlich bei den schwächsten Säurelösungen. Doch erklärt dies immer noch nicht ganz die beobachteten Zahlen.

Bei $30^{\circ}$ tritt in $0,00125 \mathrm{H}_{2} \mathrm{SO}_{4}$ keine Lackfärbung ein; nehmen wir an, dass dieser Säurebetrag durch das Blut neutralisirt wird (ein sicher $\mathrm{zu}$ hoher Werth, denn eine voliständige Neutralisation war ja nicht eingetreten), so kämen danach in den anderen Lösungen nicht die vollen Werthe der H-Ionen, sondern geringere zur Geltung, also statt 0,005 der Werth $0,005-0,00125$. Die Concentrationswerthe der H-Ionen, welche wirklich zur Wirkung kommen, verhalten sich also anders, nämlich:

$\begin{array}{lcccc}\text { Eprouvette . . . . } & 1 & 2 & 3 & 4 \\ \mathrm{H}_{2} \mathrm{SO}_{4} \text {-Concentration } & 0,005-0,00125 & 0,004-0,00125 & 0,0025-0,00125 & 0,002-0,00125 \\ & 0,00375 & 0,00275 & 0,00125 & 0,00075 \\ \text { Eintritt d. Lackfarbe } & 8^{\prime} & 10^{\prime} & 48^{\prime} & 70^{\prime}\end{array}$

Bei 4 haben wir gegen 1 ein Fünftel der Concentration, aber fast das 9 fache der Zeit; bei 1 gegen 3 haben wir $1 / 3$ der Concentrationen und das 6 fache der Zeit. Also trotz der reichlichen Correctur, durch welche der Einfluss des alkalischen Serums mehr als ausgeglichen ist, keine Proportionalität zwischen Reactionszeit und Concentration der H-Ionen.

Wenn das Lackfarbenwerden rother Blutscheiben in indifferenten Rohrzuckerlösungen durch verschiedene Säuren unter Bedingungen erfolgt, welche vermuthen lassen, dass die freien Wasserstoffionen für das Eintreten der Reaction verantwortlich zu machen sind, daun ist in diesem Falle der Vorgang des Lackfarbenwerdens als ein katalytischer aufzufassen. Handelt es sich demnach um Katalyse durch H-Ionen, so müsste die Reactionsgeschwindigkeit der Zahl der Wasserstoffionen proportional sein. Das scheint annähernd zu stimmen beim Vergleichen der Wirkung verschiedener Săuren. Bei Prüfung verschiedener Concentrationen derselben Säure war jedoch keine, auch nicht annähernde Propartionalität festzustellen, da einmal bei der ungemein geringen Anzahl von H-Ionen, welche schon Lackfarbenwerden bewirken, ein Verlust an solchen durch Neutralisation mit den OH-Ionen des zugesetzten Blutes sehr in die Waage fällt und das Resultat ganz erheblich beeinflusst; ferner auch ist zu beachten, dass wir den Einfluss der Salze des zugesetzten Blutes nicht vergessen dürfen. Es sind also die Versuche noch weiter zu variiren, und dieselben versprechen noch 
weitere Resultate, welche höchstwahrscheinlich sich doch in eine mathematische Formel fassen lassen, welche jetzt sehon aufzustellen verfrüht wäre.

Die Beeinflussung der Reactionsgeschwindigkeit durch die Temperatur, welche sich in einem schnellen Anwachsen der Geschwindigkeit kundgab, in einer Formel wiederzugeben, dazu sind die Versuche noch nicht zahlreich genug. Annähernd können wir feststellen, dass mit einem Ansteigen der Temperatur um $10^{\circ}$ beinahe eine Verdoppelung der Geschwindigkeit eintritt.

\section{Einfluss von Basen auf rothe Blutscheiben.}

Basen in wässeriger Lösung wirken zerstörend auf rothe Blutscheiben ein: diese werden lackfarben, dann braun bis schwarz. Dass aber doch eine gewisse Resistenz der rothen Blutscheiben gegen Laugen besteht, ergibt sich daraus, dass sich schliesslich eine Verdünnung finden lässt, welche noch stark alkalisch reagirt, aber die Hämoglobinfarbe der Blutscheiben nicht vernichtet. Lösungen von $\mathrm{K}_{2} \mathrm{O}$ wie auch $\mathrm{Na}_{2} \mathrm{O}$ von gleichem osmotischem Druck wie das Serum zerstören die rothen Blutscheiben sofort; erst in sehr viel schwächeren Concentrationen bleibt die rothe Farbe des Blutes einige Zeit unverändert. Der Einfluss von Laugen auf rotbe Blutscheiben, speciell ihr Vermögen, lackfarben zu machen, muss daher in derselben Weise geprüft werden wie bei den Säuren, nämlich unter Vorsichtsmaassregeln, durch welche die Wirkung des Wassers ausgeschaltet wird.

\section{Kali.}

\section{Versuch 1.}

8 Lösungen von Aetzkali in Wasser $0,6 \%$ bis $1,12 \%$ wurden mit Blut versetzt, in allen wurde das Blut s o f o $\mathrm{t}$ lackfarben, braun im durchfallenden Licht, braunroth im auffallenden.

\section{Versuch 2.}

Von einer $0,8 \%$ igen $\mathrm{K}_{2} \mathrm{O}$-Lösung wurden je $5 \mathrm{ccm}$ mit Rohrzuckerlösung in verschiedenem Grade verdünnt.

$\begin{array}{llllllllllll}0,8 \% \text { ige } \mathrm{K}_{2} \mathrm{O} \text {-Lösung . . . . . . . . . . } & 5 & 5 & 5 & 5 & 5 & 5 & 5 & 5 \mathrm{ccm} \\ 9,4 \% \text { ige Rohrzuckerlösung. . . . . . . . } & 3 & 4 & 5 & 6 & 7 & 8 & 9 & 10 \mathrm{ccm} \\ \text { Eprouvette. . . . . . . . . . . . Nr. } & 1 & 2 & 3 & 4 & 5 & 6 & 7 & 8\end{array}$

Nr. 1 und 2 wurden sofort lackfarben und braun; ron Nr. 3 ab wurde erst Lackfarbenwerden, dann Bräunung beobachtet; innerhalb 7 Minuten waren alle Proben lackfarben. 


\section{Versuch 3.}

$0,8 \%$ ige $\mathrm{K}_{2} \mathrm{O}$-Lösung $\cdot 2$ $9,4 \%$ ige Rohrzuckerlös. 5

$\begin{array}{llllccc}2 & 2 & 2 & 2 & 2 & 2 & 2 \mathrm{ccm} \\ \mathbf{6} & 7 & 8 & 9 & \mathbf{1 0} & \mathbf{1 1} & \mathbf{1 2} \mathrm{ccm} \\ 2 & 3 & 4 & 5 & 6 & 7 & 8\end{array}$

Eprouvette . . . Nr. 1

$7^{\text {h }} 3^{\prime}$ mit Fingerblut beschickt.

$7 \mathrm{~h} 45$ '. . . . lack Beginn lack $3-8$ alle noch deckfarben.

am nächsten Tage

$12 \mathrm{~h} 15^{\prime}$.....

$\begin{array}{cccc}1 & 2 & 3 & 4 \\ \text { lack } & \text { lack } & \text { lack } & \text { lack }\end{array}$

also nach 17 Std.

roth- roth- roth ruth braun braun

$\begin{array}{ccc}5 & 6 & 8 \\ \text { lack } & \begin{array}{c}\text { roth } \\ \text { lack lackf. } \\ \text { Sediment }\end{array} & \begin{array}{c}\text { rothes lackf. } \\ \text { Sediment, } \\ \text { rothe Farbe } \\ \text { nach oben hin } \\ \text { abnehmend. }\end{array}\end{array}$

\section{Versuch 4.}

$0,8 \%$ ige $\mathrm{K}_{2} \mathrm{O}$-Lösung. . . . 2

$9,4 \%$ ige Rohrzuckerlösung . 7

$\begin{array}{rrrrrr}2 & 2 & 2 & 2 & 2 & \mathrm{ccm} \\ 8 & 9 & 10 & \mathbf{1 1} & \mathbf{1 2} \mathrm{ccm} \\ 2 & 3 & 4 & 5 & 6\end{array}$

Eprouvette ..... Nr. 1

$12 \mathrm{~h} 45^{\prime}$ mit Fingerblut beschickt und in's Bad von $38^{\circ} \mathrm{C}$. gesetzt.

Lackfarben um . . . . $12 \mathrm{~h} 55^{\prime} \quad 12^{\mathrm{h}} 58^{\prime} \quad 1^{\mathrm{h}} \quad 1^{\mathrm{h}} 3^{\prime} \quad 1^{\mathrm{h}} 7^{\prime} 1^{\mathrm{h}} 13^{\prime}$

also nach. . . . . . 10 10' 13' 10 $^{\prime} \quad 18^{\prime} \quad 22^{\prime} \quad \mathbf{2 8}^{\prime}$

\section{Versuch 5.}

$\begin{array}{llllccr}\text { Eprouvette . . . . Nr. } & \mathbf{1} & \mathbf{2} & \mathbf{3} & \mathbf{4} & \mathbf{5} & \mathbf{6} \\ 0,8 \% \text { ige } \mathrm{K}_{2} \mathrm{O} \text {-Lösung . . } & 2 & 2 & 2 & 2 & 2 & 2 \\ 9,4 \% \text { ige Rohrzuckerlös. . } & \mathbf{7} & \mathbf{8} & \mathbf{9} & \mathbf{1 0} & \mathbf{1 1} & \mathbf{1 2}\end{array}$

$12^{\mathrm{h}} 45^{\prime}$ mit Fingerblut beschickt, aber bei $8^{\circ} \mathrm{C}$. stehen lassen; alle 6 sedimentiren; am nächsten Tag $5 \mathrm{~h} 30^{\prime} \mathrm{N}$., also nach fast 29 Stunden, zeigen alle 6 Eprouvetten Sedimentation mit ca. $1 \mathrm{ccm}$ klarer, farbloser überstehender Lösung. In Epronvette 1 ist das Sediment lackfarben, in 2 deutlicher Beginn der Lackfärbung. $3-6$ werden $6 \mathrm{~h} 25^{\prime}$ in ein Bad von $25^{\circ} \mathrm{C}$. gesetzt:

$$
34 \quad 5
$$

Lackfärbung tritt ein . . . . . 7 h $20^{\prime} \quad 7^{\mathrm{h}} 45^{\prime} \quad 8$ h $5^{\prime}$ nicht abgewartet also nach......... $55^{\prime} \quad 80^{\prime} \quad 100^{\prime}$

In Anbetracht dessen, dass, trotz der Undurchgängigkeit der "Wand" der rothen Blutscheiben für $\mathrm{K}$-Ionen, in $\mathrm{K}_{2} \mathrm{O}$-Lösungen die rothen Blutscheiben sich so verhalten, als würden sie in reines Wasser versetzt, müssen wir uns fragen, ob wir unsere neutrale Rohrzuckerlösung mit der $\mathrm{K}_{2} \mathrm{O}$-Lösung verdünnen dürfen, ohne ihre Neutralwirkung zu schädigen. Was wir bei diesen Verdünnungen beobachten, kann also nicht ohne Weiteres als Wirkung der alkalischen Lösung angesehen werden. Wollen wir die Wirkung des Wassers bei unseren Versuchen ausschalten, so müssen wir, wie bei den Säuren, nicht eine Neutrallösung mit einer $\mathrm{K}_{2} \mathrm{O}-\mathrm{L}$ ösung verdünnen, sondern wir müssen eine Reihe Neutrallösungen haben, welche in verschiedener 
Concentration ausserdem $\mathrm{K}_{2} \mathrm{O}$ enthalten; dies erreichen wir dureh Verdünnen der doppelten Neutrallösung mit gleichen Theilen verschieden concentrirter $\mathrm{K}_{2} \mathrm{O}$-Lösungen.

Folgender Versuch zeigt deutlich den Finfluss dieser Massregel.

\section{Versuch 6.}

In 0,8\% iger $\mathrm{K}_{2} \mathrm{O}$-Lösung wird Blut innerhalb 1 Minute lackfarben. In Mischungen von:

$0,8 \%$ iger $\mathrm{K}_{2} \mathrm{O}$-Lösung mit $\cdot$. . 2

$9,4 \%$ iger Rohrzuckerlösung . . 2

$2 \times 9,4 \%$ iger Rohrzuckerlösung .

$\begin{array}{llll}1 & 2 & 2 & 3 \\ & 2 & 3 & 4\end{array}$

wird $4^{\text {h }} 24^{1 / 2^{\prime}}$ defibr. Schweineblut zugesetzt und bei $18^{\circ}$ gehalten.

Lackfärbung tritt ein . . . . 4 h $31^{\prime} \quad 5$ h $42^{\prime} \quad 4 \mathrm{~h}^{\prime} 47^{\prime}$ nicht abgewartet also nach . . . . . . . . . $5^{1 / 2^{\prime}} \quad 7^{\prime} \quad 22^{1 / 2}{ }^{\prime}$

Demnach ist bei der Verdünnung der 9,4\%igen Rohrzuckerlösung durch die $\mathrm{K}_{2} \mathrm{O}$-Lösung ausser durch die $\mathrm{OH}$-Ionen auch durch die Verdünnung mit Wasser eine Schädigung der Blutscheiben erfolgt, wesshalb eher Lackfärbung eintritt als bei der Mischung der $\mathrm{K}_{2} \mathrm{O}$-Lösung mit der $2 \times 9,4 \%$ igen Rohrzuckerlösung, bei welcher die Schädigung durch die $\mathrm{W}$ asserverdünnung wegfällt.

In der Folge wurden desshalb die Versuche jetzt so wie bei den Säuren angestellt.

\section{Versuch 7 .}

$\begin{array}{llllllllllll}0,8 \% \mathrm{~K}_{2} \mathrm{O} & \cdot & \cdot & \cdot & \cdot & . & 5 & 5 & 5 & 5 & 5 & 5 \mathrm{ccm} \\ \text { Aq. dest } & . & . & . & . & . & 0 & \mathbf{1} & \mathbf{2} & \mathbf{3} & \mathbf{4} & \mathbf{5} \mathrm{ccm}\end{array}$

Von jeder Concentration je $2 \mathrm{ccm}$ mit je $2 \mathrm{ccm} 2 \times 9,4$ iger Rohrzuckerlösung gemischt, mit Blut versetzt und bei den Temperaturen $18^{\circ}, 25^{\circ}$ und $37^{\circ} \mathrm{zum}$ Sedimentiren aufgestellt.

Die $3 \times 6$ Eprouvetten wurden $4^{\text {h }} \mathbf{5 6}^{\prime}$ mit defibr. Schweineblut beschickt.

\begin{tabular}{|c|c|c|c|c|c|c|c|c|}
\hline $\begin{array}{l}\text { Lackfärbung } \\
\text { in Eprouvette }\end{array}$ & trat & $\begin{array}{l}\text { ein: be } \\
\text {. Nr. }\end{array}$ & $\begin{array}{c}0,4 \\
1\end{array}$ & 2 & $\begin{array}{c}0,286 \\
3\end{array}$ & $\begin{array}{c}0,25 \\
4\end{array}$ & $\begin{array}{c}0,222 . . \\
5\end{array}$ & $\begin{array}{c}0,2 \% \mathrm{~K}_{2} \mathrm{U} \\
6\end{array}$ \\
\hline $\begin{array}{l}\text { lei } \mathbf{1 8}^{0} \\
\text { lso nach }\end{array}$ & . & . & $\begin{array}{c}5 \text { h } 20^{\prime} \\
\mathbf{2 4}^{\prime}\end{array}$ & $\begin{array}{c}5 \text { h } 42^{\prime} \\
46^{\prime}\end{array}$ & $\begin{array}{c}5 \text { h } 46^{\prime} \\
50^{\prime}\end{array}$ & $\begin{array}{c}6 \text { h } 12^{\prime} \\
76^{\prime}\end{array}$ & nicht & ompontot \\
\hline$\frac{25^{\circ}}{\text { nach. }}$ & • & . & $\begin{array}{c}5 \text { h } 11^{\prime} \\
15^{\prime}\end{array}$ & $\begin{array}{c}5 \text { h } 26^{\prime} \\
30^{\prime}\end{array}$ & $\begin{array}{l}5 \text { h } 26^{\prime} \\
\mathbf{3 0} 0^{\prime}\end{array}$ & $\begin{array}{c}5 \text { h } 37^{\prime} \\
41^{\prime}\end{array}$ & $\begin{array}{c}5 \text { h } 43^{\prime} \\
47^{\prime}\end{array}$ & $\begin{array}{c}5 \text { h } 55^{\prime} \\
59^{\prime}\end{array}$ \\
\hline${ }^{\circ}$ & . & & $\begin{array}{c}5 \mathrm{~h} 1^{\prime} \\
5^{\prime}\end{array}$ & $\begin{array}{c}5 \text { b } 5^{\prime} \\
9^{\prime}\end{array}$ & $\begin{array}{c}5 \text { h } 6^{\prime} \\
10^{\prime}\end{array}$ & $\begin{array}{c}5 \mathrm{~h} 6^{1 / 2^{\prime}} \\
10^{1 / 2^{\prime}}\end{array}$ & $\begin{array}{c}5 \text { h } 8^{\prime} \\
12^{\prime}\end{array}$ & $\begin{array}{c}5 \text { h } 10^{\prime} \\
14^{\prime}\end{array}$ \\
\hline
\end{tabular}




\section{Ammoniak.}

Ammoniak $\mathrm{NH}_{3}$ in Wasser gelöst wird zu Ammoniumbydroxyd $\mathrm{NH}_{4} \mathrm{OH}$; dieses dissociirt theilweise in die Ionen $\mathrm{NH}_{4}{ }_{4}$ und $\mathrm{OH}^{\prime}$.

Da wir die rothen Blutscheiben für $\mathrm{NH}_{4}$-Ionen durchgängig annehmen mussten, war das Lackfarbenwerden der rothen Blutkörperchen in Lösungen von Ammoniak leicht zu erklären; es findet sich keine Concentration von Liq. ammon. caustic, in welcher die Blutscheiben nicht lackfarben werden.

Allein, mischen wir neutrale Salzlösungen mit Ammoniaklösungen, so bleiben die rothen Blutscheiben in solchen Gemischen wohl deckfarben, aber nur für eine gewisse Zeit; schliesslich tritt doch Lackfärbung ein, wenn auch erst nach Tagen. Nehmen wir 24 Stunden als Grenze an, innerbalb welcher Zeit der schädigende Einfluss des Ammoniaks oder der Ammoniumionen oder der $\mathrm{OH}^{\prime}$-Ionen sich geltend machen muss, so liess sich durch Versuche die Concentration der Ammoniaklösung finden, welche die rothen Blutscheiben nicht mehr schädigt; doch zeigte sich auch bald, dass hier ausser der Zeit auch wieder die Temperatur eine Rolle spielt.

Von den Vorversuchen sei nur einer hier wiedergegeben.

\section{Versuch 8.}

$4 \mathrm{ccm}$ Liq. à m mon. caustic. mit $20 \mathrm{ccm} 9,4$,iger Rohrzuckerlösung ist die Stammlösung; $1 \mathrm{ccm}$ dieser Stammlösung wird mit 5--12 ccm 9,4\% iger Rohrzuckerlösung verdünnt.

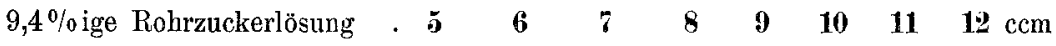
$\begin{array}{lllllllllll}\text { Eprouvette . . . . . . . . } & 1 & 2 & 3 & 4 & 5 & 6 & 7 & 8\end{array}$

12 h $40^{\prime}$ Blutzusatz (defibr. Schweineblut)

im Bad von $37^{\circ}$ ist $1^{\text {h }} 15^{\prime} \mathrm{Nr}$. 1 lackfarben, also nach $35^{\prime}$.

4 h $\mathbf{3 0}^{\prime}$, also nach 4 Stunden lack lack lack lack lack lack tı üb trüb

Im Bad von $\mathbf{2 5}^{\circ}$ bleiben alle über eine Stunde deckfarben. $4^{\mathrm{h}} 30^{\prime}$ beginnt Nr. 1 lackfarben zu werden, also nach fast 3 Stunden; 10-12 sind sedimentirt; am nächsten Tag sind alle 2-8 sedimentirt, aber das Sediment ist lackfarben; die überstehende Flüssigkeit in $2-5$ ist roth, in 7 und 8 farblos-klar.

Um den Einfluss der Wasserverdünnung auszuschalten, werden auch Versuche mit $2 \times 9,4 \%$ iger Rohrzuckerlösung in der beschriebenen Weise angestellt.

\section{Versuch 9.}

Liq. a mm on. caust. off. . . . . . . . . $2 \begin{array}{ccccccc}2 & 3 & 4 & 5 & 6 & 7 & \mathrm{ccm}\end{array}$

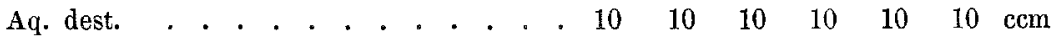

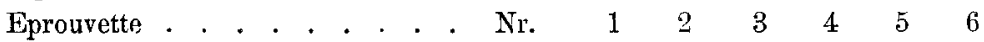
Jede Eprouvette enthält $5 \mathrm{ccm}$ der betr. Ammon.-Lösung und $2 \mathrm{ccm} 2 \times 9,4 \%$ iger Rohrzuckerlösung. 
12 h $3^{\prime}$ werden sie mit 1 Tropfen defibr. Schweineblutes beschickt.

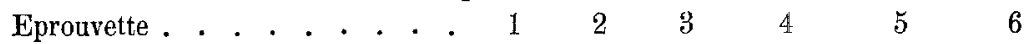

Lackfärbung tritt ein bei $\mathbf{3 7}{ }^{\circ}$ : nicht abgewartet 1 h $12^{\prime} 11^{\text {to }} 2^{\prime} 12$ h $51^{\prime} 12$ h $42^{\prime}$ also nach . . . . . . . . . . . . . 68 $68^{\prime}$ 58 $48^{\prime}$ 38' Bei 25 und $18^{\circ}$ trat innerhalb 24 Stunden keine Lackfärburg ein.

\section{Versuch 10.}

Liq. ammon. caust. off. $\quad$. . . . $8 \begin{array}{ccccc}8 & 10 & 12 & 14 & 16\end{array}$ Aq. dest. . . . . . . . . . . $10 \quad 10 \quad 10 \quad 10 \quad 10 \mathrm{ccm}$

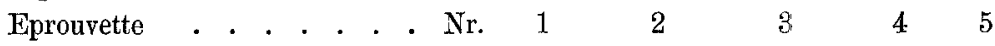

Mit der Ammon.-Lösung u. $2 \times 9,4 \%$ iger Rohrzuckerlösung a je 2 ccm gefüllt.

12 h $58^{\prime}$ mit je 1 Tropfen defibr. Schweineblutes beschickt.

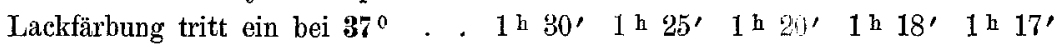

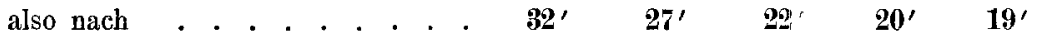

Bei $25^{\circ}$ tritt innerhalb einer $S$ tunde keine Lackfä̀ìng ein, aber nach drei Stunden findet sich dieselbe bei allen.

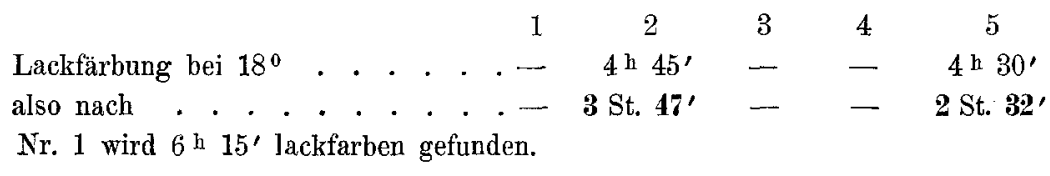

\section{Kaliumcarbonat.}

Obgleich sich die blutkörperchenauflösende Kraft des Wassers auch durch Kalium- und Natriumcarbonat aufheben lässt - denn es lässt sich für beide eine Concentration (1,1\% und $1,9 \%$ ) finden, in der die Blutscheiben ihr Volumen behalten - so zeigt doch das Lackfarbenwerden in diesen Lösungen nach längerer Zeit an, dass die Schutzwirkung der Carbonate gegen das Wasser eine unvollkommene ist, oder dass in den Carbonatlösungen selbst blutscheibenschädigende Momente enthalten sind.

\section{Versuch 11.}

In einer $2,07 \%$ igen $\mathrm{K}_{2} \mathrm{CO}_{3}$-Iösung wird 1 Tropfen Blut zum Sedimentiren aufgestellt. $4^{\text {h }} 30^{\prime}$ N. Das Blut wird lackfarben

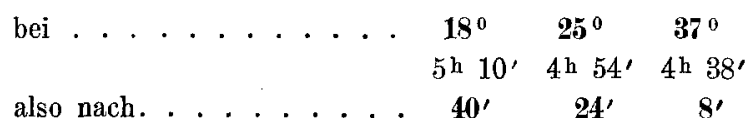

Versuch 12.

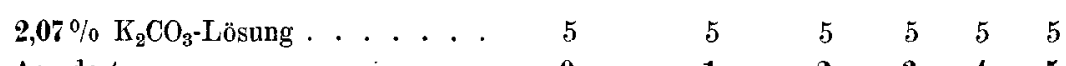

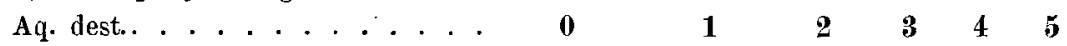

Mit $2 \times 9,4 \%$ iger Rohrzuckerlösung zu gleichen Theilen wird 1 Tropfen Blut versetzt 3 h $38^{\prime}$. Das Blut wird lackfarben

bei $37^{\circ} \ldots \ldots 4^{\text {h }} 45^{\prime}$

5 h $15^{\prime} \quad 5^{\text {h h }} 30$

5 h $45^{\prime}$

also nach

$77^{\prime}$

107' 129'

187' 


\section{Versuch 13.}

4,15\% \% ige $\mathrm{K}_{2} \mathrm{CO}_{3}$-Lösung, also d oppelte Concentration; alles Andere sonst wie oben. Blut wird lackfarben bei $37^{\circ}$ nach 39, 45, 52 Min. in den Eprouvetten 1, 2 u.3.

Besprechung der Versuche mit alkalischen Lösungen.

Das Serum, in welchem die rothen Blutscheiben sich Tage lang unversehrt erhalten, reagirt alkalisch. Von Kaliumearbonat und Natriumcarbonat lassen sich mit dem Hämatokrit Lösungen finden $(1 \%$ resp. $0,9 \%)$, in welchen die rothen Blutscheiben das gleiche Volumen haben wie im Plasma, und diese Lösungen sind auch annähernd mit dem Plasma isosmotisch; gleichwohl halten sich die rothen Blutscheiben in diesen Lösungen nicht lange, sondern werden lackfarben. Von Natron- und Kalilauge (V. 1) lässt sich überhaupt keine Concentration finden, in der die rothen Blutscheiben als solche erhalten bleiben, sondern nur ganz schwache Concentrationen zerstören die rothe Blutfarbe nicht; alle stärkeren bewirken Braun- bis Schwarzfärbung.

In Natron- und Kalilösungen sind nur Na- resp. K und OH-Ionen, sowie Wasser. Na-, K- und $\mathrm{OH}-I$ Ionen finden sich auch in den $\mathrm{Na}-$ und K-Carbonatlösungen; sie sind auch im Plasma und Serum; in den letzteren sind sie unschädlich, bewirken kein Lackfarbenwerden. Na-, K- sowie OH-Ionen an sich können desshalb nicht ohne Weiteres als das blutkörperchenschädigende Moment angesehen werden. Wenn wir nun in den drei Flüssigkeiten, Serum, Natroncarbonatlösung und Natronlösung, ein ganz verschiedenes Verhalten der Blutscheiben beobachten, so dürfen wir die schädigende Wirkung der Natronlösung nicht den Na- oder OH-Ionen schlechtweg zuschreiben, sondern entweder die Concentration der Na- oder $\mathrm{OH}-$ Ionen dafür verantwortlich machen, oder wir müssen annehmen, dass die schädigende Wirkung der Na- oder $\mathrm{OH}-\mathrm{Ionen}$ durch die Anwesenheit an d er er Salze oder sonstiger Moleküle aufgehoben wird.

Na- und K-Ionen kommen als schädigende Momente nicht in Frage, auch wenn ihre Concentration eine hohe ist, denn in Neutralsalzen $\left(\mathrm{NaCl}\right.$ und $\mathrm{KCl}, \mathrm{NaNO}_{3}$ und $\mathrm{KNO}_{3}$, sowie $\mathrm{Na}_{2} \mathrm{SO}_{4}$ und $\mathrm{K}_{2} \mathrm{SO}_{4}$ u. s. w.) tritt keine Schädigung der rothen Blutscheiben ein, trotz hoher Conceutration an Na- resp. K-Ionen. Es bleiben also nur die OH-Ionen übrig.

Für diese OH-Ionen besteht aber zwischen den drei Flüssigkeiten: Serum, Natroncarbonat und Natronlösung, ein bedeutender 
Unterschied in Bezug auf die Concentration derselben. Serum hat die geringste, Natronlösung die stärkste Concentration an $\mathrm{OH}-$ Ionen bei gleichem osmotischem Druck aller drei.

Dieser Einfluss der Concentration der OH-Ionen auf das Lackfarbenwerden der rothen Blutscheiben tritt schon in Versuch 3 zu Tage. Bei hoher Concentration tritt Lackfarbe eher auf als bei geringer. Den Einfluss der Zeit auf den Eintritt der Reaction des Lackfarbenwerdens gleichzeitig mit dem Einfluss der Temperatur zeigen Versuch 4 und 5.

Vergleichen wir nach Versuch 4, wie sich Concentration und Zeitdauer bis zum Eintritt der Reaction gegenseitig beeinflussen, so finden wir kein constantes Verhältniss.

$\begin{array}{rlcccccc} & & 1 & 2 & 3 & 4 & 5 & 6 \\ \mathrm{~K}_{2} \mathrm{O} \% \text {-Gehalt. } & c=0,18 & 0,16 & 0,145 & 0,133 & 0,123 & 0,114 \\ \text { Zeit in Minuten } & t=10 & 13 & 15 & 18 & 22 & 28 \\ c: t & =1,8 & 2,08 & 2,17 & 2,39 & 2,5 & 3,19 .\end{array}$

Es fragt sich, ob dieser Versuch 4 in solcher Weise verwerthet werden kann, denn in diesem kommt neben verschiedenem $\mathrm{K}_{2} \mathrm{O}$ Gehalt noch verschiedener Zuckergehalt in Betracht. Allein verschiedene $\mathrm{K}_{2} \mathrm{O}$-Concentration bei gleicher Zuckerconcentration der Lösungen bietet Versuch 7 .

Aus Versuch 7 ergibt sich:

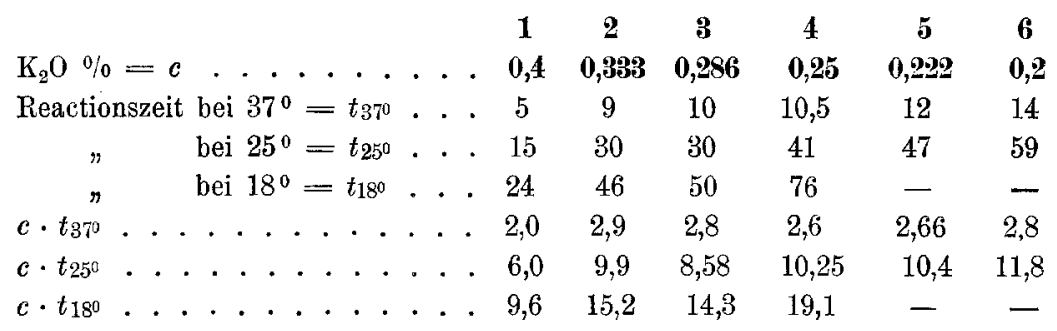

Aus diesem Versuch lässt sich eher sagen, dass die Geschwindigkeit, mit welcher die Reaction des Lackfarbenwerdens eintritt, der Concentration annähernd proportional ist. Da nun der Concentration der $\mathrm{K}_{2} \mathrm{O}$-Lösung auch ihr Gehalt an OH-Ionen bei diesem Grad der Verdünnung mit verschwindendem Fehler gleichgesetzt werden kann, könnten wir feststellen, dass bei gleicher Temperatur die Geschwindigkeit des Reactionseintritts, des Lackfarbenwerdens, der Concentration der OH-Ionen annähernd proportional ist. 
Versuch 12 und 13 ergeben das Gleiche bei $\mathrm{K}_{2} \mathrm{CO}_{3}$-Lösungen: bei $37^{\circ}$ Lackfärbung nach . . . . . . 77' 107' 122' bei $37^{\circ}$ und doppelter Concentration . . $39 \quad 45 \quad 52$

Die Versuche mit Ammoniak passen vollkommen zu denen mit $\mathrm{K}_{2} \mathrm{O}$-Lösungen. Die Abbängigkeit des Lackfarbenwerdens von Concentration, Zeit und Temperatur ist deutlich erkennbar.

Vergleichen wir nun die Ammoniakconcentrationen mit den $\mathrm{K}_{2} \mathrm{O}$-Concentrationen, so finden wir zwei annähernd gleich wirkende Lösungen :

Versuch 7. Pipette 5 wird bei $37^{\circ}$ in 14 Minuten lackfarben 10. " 7 " $37^{\circ}, 19$ "

Demnach wirken $0,2 \% \mathrm{~K}_{2} \mathrm{O}$ (in $9,4 \%$ iger Rohrzuckerlösung) gerade so auf rothe Blutscheiben wie $3 \% \mathrm{NH}_{3}$, oder 0,042 g-mol.- $\%$ KOH wirken wie $1,8 \mathrm{~g}$-mol.- $\% \mathrm{NH}_{4} \mathrm{OH}$; es bedarf einer etwa $42 \mathrm{Mal}$ so starken Ammoniaklösung als Kalilösung, um Lackfarbenwerden der rothen Blutscheiben $\mathrm{zu}$ erzielen. Da Kali in Wasser stärker dissociirt als Ammoniak, enthält eive gleich starke KOH-Lösung ( $\mathrm{KOH}=\mathrm{K}^{\cdot}+\mathrm{OH}^{\prime}$ ) mehr OH-Ionen als eine Ammoniaklösung $\left(\mathrm{NH}_{4} \mathrm{OH}=\mathrm{NH}_{4} \cdot+\mathrm{OH}^{\prime}\right)$, leitet desshalb den elektrischen Strom besser, und zwar leitet die KOH-Lösung ca. 40-50 Mal besser als $\mathrm{NH}_{4} \mathrm{OH}$. Wir sehen daraus, dass die gleiche Wirkung der $0,042 \%$ igen $\mathrm{KOH}-\mathrm{Lösung}$ und 1,8\% \% igen $\mathrm{NH}_{4} \mathrm{OH}$-Lösung bedingt ist durch den gleichen Gehalt an $\mathrm{OH}-\mathrm{I}$ onen.

Der Einfluss der Temperatur auf die Geschwindigkeit, mit welcher unsere Reaction, die Lackfärbung, eintritt, lässt sich am besten aus Versuch 7 und 11 erkennen. Beide Versuche zeigen deutlich, dass die Geschwindigkeit mit wechselnder Temperatur zunimmt, und zwar mit Beschlennigung. Während zwischen $18^{\circ}$ und $25^{\circ}$ auf $1^{\circ}$ Temperaturzuwachs eine Verkürzung der Reactionszeit um 3, 2,3 und 1,3 Minuten kommt, entspricht zwischen $25^{\circ}$ und $37^{\circ}$ einem Temperaturzuwachs von $1^{\circ}$ eine Zeitverkürzung von 1,7, 1,3 und 0,8 Minuten.

Das Lackfarbenwerden rother Blutscheiben in alkalischen Medien, durch Kali. Ammoniak, Kaliumearbonat alkalisch gemachter Rohrzuckerlösung, ist di e Folge des Gehalts dieser Medien an OH-Ionen. Die Geschwindigkeit des Eintritts der Lackfärbung ist der Menge freier OHIonen annähernd proportional, und mit zunehmender 
Temperatur nimmt die Geschwindigkeit mit Beschleunigung zu.

Der ganze Vorgang verläuft vollkommen analog dem Vorgang der Verseifung eines Esters durch Hydroxylionen.

\section{Einfluss einer Reihe verschiedener Stoffe.}

Als ganz besonders blutkörperchenauflösend werden Stoffe wie Aether, Chloroform, Schwefelkohlenstoff u. a. bezeichnet; von ihnen genügen schon geringe Mengen, um, mit einer Quantität Blut geschüttelt, sofort oder nach einigen Minuten dieses lackfarben zu machen.

Ich war nun vollkommen überrascht, dass bei meiner Versuchsanordnung das Lackfarbenwerden der Blutkörperchen sehr oft ausblieb. Bei meinen ersten Versuchen (Mai 1900) hatte ich die Neutrallösungen (Rohrzuckerlösung und $\mathrm{Na}_{2} \mathrm{SO}_{4}$-Lösung) mit Chloroform geschüttelt, einige Tage stehen lassen, danach die überstehende chloroformgesättigte Lösung abgegossen. Diese gesättigte Lösung wurde mit der Neutrallösung verschiedenfach verdünnt, so dass eine Reihe von Lösungen mit verschiedenem Chloroformgehalt zur Verfügung stand; in diese wurden gleiche Mengen, 1-3 Tropfen, Fingerblut aufgeschwemmt und zum Sedimentiren hingestellt. Der Erfolg war ein ganz verschiedener. Zuweilen wurde das Blut in dem gesättigten Chloroformgemisch s of or t lackfarben, zuweilen zeigte sich auch nach einigen Tagen noch keine Spur von Lackfarbenwerden.

Am 13. Mai $190012^{\mathrm{h}} 20^{\prime}$ wurden vier Proben, eine gesättigte Chloroform- $\mathrm{Na}_{2} \mathrm{SO}_{4}$-Lösung mit drei Verdünnungen derselben, mit Blut beschickt. Alle vier Proben blieben deckfarben; nach 3/4 Stunde war in allen drei Sedimentation zu beobachten, aber bei der ersten Probe war die obenstehende Flüssigkeit roth gefärbt; am nächsten Tage, 14. Mai, $12 \mathrm{~h}$ war die erste Probe vollständig lackfarben; am 14. Mai Abends beginnt die zweite Probe lackfarben zu werden, und am 15. Mai zeigt diese vollständige Auflösung.

Ein am 14. Mai sofort mit denselben Lösungen wiederholter Versuch verlief anders. Am 15. Mai waren alle Proben klar sedimentirt; erst am 16. Mai zeigte Probe 1 Lackfarbenwerden, alle anderen nicht.

Die Versuche mit Chloroform-Rohrzuckerlö̀sungsgemisch zeigten 
dieselbe Inconstanz der Resultate, es liess sich keine Beziehung finden zwischen Chloroformencentration und Zeit der Einwirkung. Zuweilen löste die gesättigte Chloroformneutrallösung die Blutscheiben sofort auf, zuweilen auch nach einigen Tagen noch nicht. Gemische von Rohrzucker-, Kochsalz- und $\mathrm{Na}_{2} \mathrm{SO}_{4}$-Lösungen mit A ether zeigten das gleiche wechselnde Verhalten.

Erst im Winter 1902 wiederholte Versuche lenkten die Aufmerksamkeit auf einen neuen Factor, der bei solchen Versuchen zu berücksichtigen ist. Um möglichst concentrirte Aetherlösungen zu bekommen, wurde die Rohrzuckerlösung (wie auch die anderen Neutrallösungen) im kalten Zimmer bei ca. $+4-8^{\circ} \mathrm{C}$. mit dem Aether versetzt, und zwar in einer Scheideflasche energisch geschüttelt und mehrere Tage ruhig stehen gelassen, bis aller Aether obenauf schwamm. Das Misslingen der Versuche mit Aether hatte ich darauf zurückgeführt, dass bei der Herstellung gesättigter Aetherlösungen vielleicht reiner Aether noch auf der Lösung sich befand, und dass dieser reine Aether in den Fällen, wo Lackfarbenwerden eintrat, dafür verantwortlich zu machen sei. Wurde aus der Scheideflasche die Aetherlösung unten ablaufen gelassen, so war diese Möglichkeit, reinen Aether auf der Lösung zu haben, ausgeschlossen. In der That schien diese Ueberlegung richtig zu sein, denn jetzt trat selbst in den mit Aether gesättigten Neutrallösungen von $\mathrm{MgSO}_{4}$ und $\mathrm{Na}_{2} \mathrm{SO}_{4}$ kein Lackfarbenwerden des Blutes ein.

Die mit Blut beschickten Proben sedimentirten alle; auch nach wiederboltem Umschütteln nach 24 und 48 Stunden trat kein Lackfarbenwerden in irgend einer Probe ein, bis einmal dieselben in ein überheiztes Zimmer gestellt wurden, und sofort trat der Umschlag bei den mit Aether gesättigten Lösungen ein.

In Folge dessen wurde von nun an immer die Temperatur aufgezeichnet, bei der die Versuche angestellt wurden, und der Einfluss der Temperatur auf das Lackfarbenwerden eingehend geprüt.

Im Zimmer von $4-8^{\circ} \mathrm{C}$. hergestellte Sättigungen von Aether in Neutrallösungen von Rohrzucker, Magnesiumsulfat, Natriumsulfat, $\mathrm{NaCl}$ wurden mit Blut beschickt. Bei dem Rohrzucker-Aethergemisch trat Lackfarbenwerden der Blutscheiben ein: Versuch 1 bei $20^{\circ} \mathrm{C}$., Versuch 2 bei $21^{\circ} \mathrm{C}$. Im $\mathrm{MgSO}_{4}$-Aethergemisch: Versuch 1 bei $20,2^{\circ} \mathrm{C}$, Versuch 2 bei $21,6^{\circ} \mathrm{C}$., Versuch 3 bei $20,4^{\circ} \mathrm{C}$.

In einer frisch bereiteten äthergesättigten Rohrzuckerlösung trat 
Lackfarbenwerden der rothen Blutkörperchen bei $22^{\circ} \mathrm{C}$. ein; iu füf Theilen dieser Stammlösung, verdünnt mit 1 Theil neutraler Rohrzuckerlösung, lösten sich die Blutscheiben bei $27-29^{\circ} \mathrm{C}$., in funf Theilen Stammlösung mit drei Theilen Verdünnung bei $33-35^{\circ} \mathrm{C}$. Aetherconcentration und Temperaturerscheinen hiernach in einem bestimmten Abhängigkeitsverhältniss in ihrer Wirkung auf die Auflösung der rothen Blutkörperchen.

Bei den weiteren Versuchen wurde dieses Wechselverhältniss systematisch in der eingangs beschriebenen Weise geprüft.

Finfluss von Aether auf rothe Blutscheiben.

\section{Versuch 1.}

Neutrallösung: 9,4\%ige Rohrzuckerlösung

versetzt mit Aether .............. . 6\% $4 \% \quad 3 \%$

Fingerblut wird lackfarben bei ......... $\mathbf{3 5}^{\mathrm{C}} \quad \mathbf{4 9 , 5} \mathbf{5}^{\circ} \mathbf{5 5}^{0} \mathrm{C}$.

\section{Fersuch 2.}

Neutrallösung: Rohrzucker versetzt mit Aether. . . . . . $6 \begin{array}{cccccc}\mathbf{6} \% & \mathbf{5}, 5 \mathbf{5} \% & \mathbf{5} \% & \mathbf{4 , 6 1} \% & \mathbf{4 , 2 8} \% & \mathbf{4} \%\end{array}$

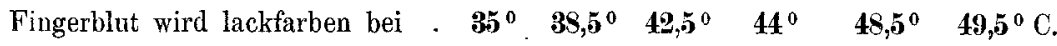

\section{Versuch 3.}

Neutrallösung: 0,9 NaNl-Lösung

$\begin{array}{llllll}\text { versetzt mit Aether ........ } & \mathbf{6} \% & \mathbf{5}, \mathbf{5 5} \% & \mathbf{5} \% & \mathbf{4 , 6 1} \% & \mathbf{4} \%\end{array}$ Fingerblut wird lackfarben bei $\ldots . \quad 35,5^{0} \quad 39^{\circ} \quad 41,5^{0} \quad 44^{\circ} \quad 47^{\circ} \mathrm{C}$.

\section{Chlor oform.}

\section{Versuch 4.}

Neutrallösung: 9,4\% Rohrzucker gesättigt mit Chloroform bei $6{ }^{\circ} \mathrm{C}$; von dieser Stammlösung werden Verdünnungen durch Versetzen von $5 \mathrm{ccm}$ derselben mit $1-5 \mathrm{ccm}$ Neutrallösung hergestellt.

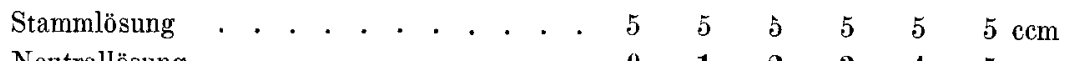

Neutrallösung

Hiervon je $5 \mathrm{ccm}$ beschickt mit Fingerblut 2 Tropfen.

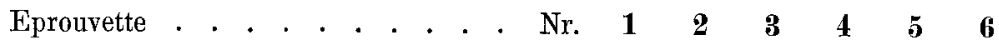

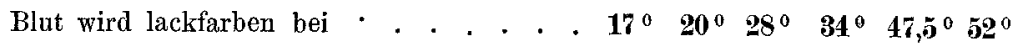

Ausser dieser Reihe, welche sofort untersucht wurde, blieb eine zweite, gleichzeitig angefertigte Reihe zum Vergleich bei $6^{\circ}$ stehen. Bei 1 und 2 tritt beim Stehen bei $+6^{\circ}$ C. Sedimentation ein, aber es ist auch schon etwas Auflösung der Blutscheiben vorhanden. $3-6$ sedimentiren bei $+6^{\circ}$; überstehende Flüssigkeit ist farblos klar. 


\section{Versuch 5 .}

Neutrallösung: $\mathrm{MgSO}_{4}$-Lösung gesättigt mit Chloroform bei $+6^{0} \mathrm{C}$, Verdünnungen wie oben.

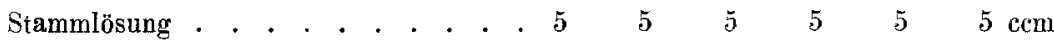

Neutrallösung . . . . . . . . . . . . . $0 \begin{array}{cccccc}0 & 1 & 2 & 3 & 4 & 5\end{array}$

Hiervon je $5 \mathrm{ccm}$ beschickt mit Fingerblut 2 Tropfen.

Eprouvette . . . . . . . . . . Nr. $1 \begin{array}{cccccc}\mathbf{2} & \mathbf{2} & \mathbf{3} & \mathbf{4} & \mathbf{5} & \mathbf{6}\end{array}$

Blut lackfarben bei . . . . . . ? $\quad 31^{\circ} \quad \mathbf{3 8 , 5} \mathbf{5}^{0} \quad \mathbf{4 2}^{\circ} \quad \mathbf{4 6}^{\circ} \quad \mathbf{4 7}^{\circ}$

Nr. 1 wird lackfarben beim Stehen bei $+10^{\circ}$; die anderen sedimentiren bei $10^{\circ}, 2$ mit überstehender röthlicher Flüssigkeit, die anderen mit weisser, klarer überstehender Flüssigkeit.

\section{Versuch 6.}

Neutrallösung: NaCl-Lösung; Sättigung mit Chloroform bei $+6^{0} \mathrm{C}$, Verdünnungen wie oben.

Stammlösung . . . . . . . . . . 55 5 5 j 5 ccm

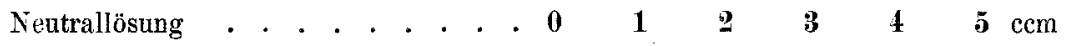

Hiervon je $5 \mathrm{ccm}$ beschickt mit 2 Tropfen Fingerblut.

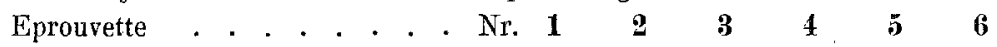

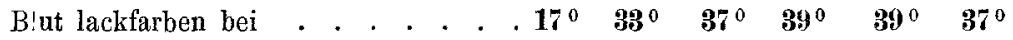

Eine andere, gleichzeitig angesetzte Reihe zeigte bei $8^{\circ} \mathrm{C}$. Zimmertemperatur nach einiger Zeit: 1. Probe vollkommen Lackfarbe; 2, 3 und 4 zeigten Sedimentation, aber die überstehende Flüssigkeit war roth gefärbt; 5 und 6 hatten vollkommen sedimentirt; überstehende Flüssigkeit war farblos-klar.

Bei der Prüfung im Wasserbad wurden 5 und 6 bei niedrigen Temperaturen lackfarben, doch dauerte dies sebr viel länger, als sonst der Umschlag eintrat. Demnach scheint die Zeit der Einwirkung des Chloroforms auf die rothen Blutscheiben gleichfalls von Einfluss zu sein. Um hierüber Klarbeit zu gewinnen, wurden die Versuche mit Kochsalz-Chloroformlösung variirt.

\section{Versuch 7.}

In der gleichen Weise wie bisher werden 6 Proben hergerichtet, Abends 7 Uhr bei $+7^{\circ} \mathrm{C}$. aufgestellt.

1

7 h $10^{\prime}$. . . . beginnende

Lackfärbung $\underbrace{2 \quad 3}$

Sedimentation

überstehende Flüssigkeit röthlich

7 h $15^{\prime}$ werden $2-6$ in ein Wasserbad von $25^{\circ} \mathrm{C}$. gesetzt; es trat

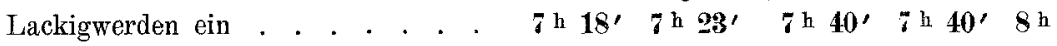




\section{Versuch 8.}

Eine zweite gleichzeitig um $7^{\mathrm{h}}$ A bends angesetzte Reihe blieb bei $+7^{\circ} \mathrm{C}$. stehen, $7 \mathrm{~h} 30^{\prime}$ fand sich 1. Lackfarbe, 2. beginnende Lackfarbe, 3-6 beginnende Sedimentation. 7 h $45^{\prime}$ 1. Lackfarbe, 2. fast ganz lack., 3. Sediment und röthliche überstehende Flüssigkeit, 4. Sed. und üb. Fl. röthlich, 5. Sed. üb. Fl. farblos, 6. Sed. üb. Fl. farblos.

Am nächsten Tage $11^{\mathrm{h}}$ Vorm. waren sämmtliche Proben lackfarben. Nr. 5 und 6 zeigten oben helle, fast farblose Sehichten, d. b. die rothen Blutscheiben sedimentirten erst, wurden nachträglich lackfarben und färbten allmählich die überstehende Flüssigkeit.

Also auch bei niederer Temperatur wirkt das Chloroform auflösend auf die rothen Blutscheiben, wenn es in NaCl-Lösung vorhanden ist und gen ügend Zeit gewährt wird.

\section{Wie verhält es sich in anderen Neutrallösungen?}

\section{Versuch 9.}

Chloroform gesättigte $\mathrm{MgSO}_{4}$-Neutrallösung und 5 Verdünnungen werden Abends $7 \mathrm{Uhr}$, bei $7^{\circ} \mathrm{C}$. mit Blut beschickt und bei dieser Temperatur zum Sedimentiren aufgestellt.

\begin{tabular}{|c|c|}
\hline Eprouvette & $\mathrm{Nr}$. \\
\hline Stammlösung . & \\
\hline $\mathrm{MgSO}_{4}$-Neutrallösung & \\
\hline
\end{tabular}
14. Januar $7 \mathrm{~h} 45^{\prime}$ Abends lack Sed. Klar sedimentirt 15. Januar $12 \mathrm{~h}$ Mittags . lack lack lack $\underbrace{\text { Har }}_{\text {klar sedimentirt }}$ üb. Fl. farblos

Anmerkung: lack $=$ Lackfarbenwerden; Sed. $=$ Sediment; üb. Fl. $=$ überstehende Flüssigkeit über dem Sediment.

Nunmehr wurden die Proben 4, 5 und 6 am 15. Januar 12 Uhr N. wieder umgeschüttelt und geprüft, bei welcher Temperatur Lackfarbenwerden eintrat.

Nr. .............. 4 . 5 6

Lackfarben bei . . . . . . . . $\mathbf{3 7}^{\circ} \quad \mathbf{4 4}^{0} \quad \mathbf{5 6}^{\circ} \mathrm{C}$.

\section{Versuch 10.}

Chloroformgesätttigte Rohrzuckerlösung und 5 Verdünnungen wurden am 14. Januar, Abds. $7 \mathrm{Uhr}$, bei $+7^{\circ} \mathrm{C}$. mit Blut beschickt und bei $7^{n} \mathrm{C}$. zum Sedimentiren aufgestellt.

$\begin{array}{lllllll}\text { Stammlösung. . . . . . } & 5 & 5 & 5 & 5 & 5 & 5 \text { ccm } \\ \text { Rohrzuckerneutrallösung. . } & \mathbf{0} & \mathbf{1} & \mathbf{2} & \mathbf{3} & \mathbf{4} & \text { 5 ccm } \\ \text { Eprouvette. . . . . Nr. } & 1 & 2 & 3 & 4 & 5 & 6\end{array}$
$7 \mathrm{~h} 45^{\prime}$. . . . . . . lack lack alle Sedimentiren, üb. Fl. weiss etw. trüb

15. Januar $11^{\mathrm{h}}$ N. . . . lack lack lack thlar sedimentirt üb. Fl. farblos. 
Bei der Prüfung der Proben 4, 5 und 6, bei welcher Temperatur dieselben lackfarben werden, ergab sich:

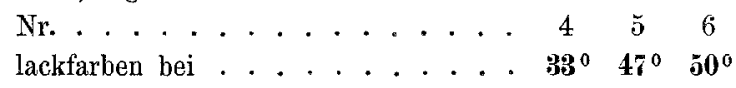

Diese mit Chloroform und Aether gewonnenen Resultate veranlassten mich nun, die früheren, anscheinend mit negativem Erfolge schon angestellten Untersuchungen mit Schwefelkohlenstoff, Toluol, Xylol zu wiederholen.

Bei der geringen Löslichkeit dieser Stoffe in Wasser blieben, um vollständige Sättigung zu erzielen, die Neutrallösungen, mit Schwefelkohlenstoff, Toluol, Xylol im Ueberschuss versetzt, ca. acht Tage im verschlossenen Gefäss stehen und wurden täglich 2-3 Mal eine Zeit lang intensiv geschüttelt.

Eine Rohrzuckerlösung, in dieser Weise bei $9^{\circ} \mathrm{C}$. mit Schwefelkohlenst off gesättigt, wurde mit Blut beschickt; das Gemisch war deckfarben; nach einiger Zeit trat Sedimentation ein; die überstehende Flüssigkeit war klar, etwas gelblich gefärbt. Beim Prüfen im Wasserbad trat Lackfarbenwerden ein bei $52^{\circ} \mathrm{C}$.

$0,9 \mathrm{NaCl}$-Lösung, bei $9^{\circ} \mathrm{C}$. mit X y lol gesättigt, mit Fingerblut versetzt, gab vollkommen deckfarbene Mischung, die nach einiger Zeit mit klarer, farbloser überstehender Flüssigkeit sedimentirte. Beim Erwärmen trat Lackfarbenwerden ein bei $56^{\circ} \mathbf{C}$.

Rohrzuckerlösung, mit Toluol bei $17-20^{\circ} \mathrm{C}$. gesättigt, wurde mit Fingerblut versetzt; dieses sedimentirte, doch war die überstehende Flüssigkeit röthlich gefärbt; bei $60,0^{\circ} \mathrm{C}$, ein anderes Mal bei $60,5^{\circ} \mathrm{C}$. wurde die Lösung lackfarben.

Weitere Versuche mit $\mathrm{Xylol}$ in $0,9 \mathrm{NaCl}-\mathrm{Lösung}$ ergaben ein Mal Lackfarbenwerden bei $63^{\circ} \mathrm{C}$., ein anderes Mal bei $64^{\circ} \mathrm{C}$.; Schwefelkohlenstoff in Rohrzuckerlösung löste Blutscheiben in zwei weiteren Versuchen beide Mal bei $55^{\circ} \mathrm{C}$.

Sedimentation bei Zimmertemperatur $\left(18-20^{\circ} \mathrm{C}\right.$.) erfolgte in diesen Fällen nach ca. 25 Minuten; die ca. ${ }^{3 / 4} \mathrm{~cm}$ hohe, klare überstehende Flüssigkeit war stets leicht roth gefärbt; nach 27 Stunden fanden sich $2 \mathrm{~cm}$ überstehender Flüssigkeit stark roth gefärbt.

Chloralhydrat.

Bei Hämatokritversuchen hatte ich schon gefunden, dass Chloralhydrat die Blutkörperchen lösende Kraft des reinen Wassers nicht 
aufhält, dagegen zeigte sich, dass Chloralhydrat, $1 \mathrm{~g}$ in $20 \mathrm{ccm}$ Rohrzuckerlösung gelöst, rothe Blutscheiben nach 4 Stunden, $1 \mathrm{~g}$ Chloralhydrat in $20 \mathrm{ccm} \mathrm{Na}_{2} \mathrm{SO}_{4}$-Lösung gelöst, nach etwas über 1 Stunde aufzulösen vermag (Sommer 1900 , wahrscheinlich also bei über $20^{\circ} \mathrm{C}$. Zimmertemperatur).

Bei wiederholter Prüfung fand sich bei 6- $8^{\circ}$ C. Zimmertemperatur, dass in wässerigen Lösungen $0,25 \%, 0,5 \% ; 1,0 \%$, $2,0 \% ; 4 \% ; 8 \%$ von Chloralhydrat rothe Blutscheiben s of ort aufgelöst wurden; eine $16 \%$ ige Lösung von Chloralhydrat in Wasser macht rothe Blutscheiben $\mathrm{n}$ icht lackfarben, sondern fällt dieselben als grobflockiges, fleischfarbenes Sediment.

Bei der Prüfung des Einflusses der Temperatur zeigte sich Versuch 11.

Chloralhydrat aufgelöst in Rohrzuckerneutrallösung.

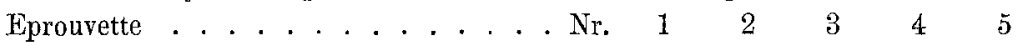

Chloralhydratgehalt. . . . . . . . . $8 \begin{array}{ccccc}8 \% & 4 \% & 2 \% & 1 \% & 0,5 \%\end{array}$

1 Tropfen $=0,05 \mathrm{ccm}$ Schweineblut defibr. wird

lackfarben bei . . . . . . . . $19^{0} \quad \mathbf{4 3}^{0} \quad \mathbf{5 3}^{0} \quad \mathbf{5 6}^{0} \quad \mathbf{6 3}^{\circ}$

Bei der Prüfung des Einflusses der Zeit der Einwirkung des Chloralhydrats fand sich:

1. zum Sedimentiren bei $6-8^{\circ}$ Zimmertemperatur aufgestellte, wie oben hergerichtete Proben sedimentirten alle ausser Nr. 1 innerhalb 24 Stunden, ohne lackfarben zu werden; Nr. 1 wurde schon beim Ansetzen $\left(19^{\circ}\right.$ C.) lackfarben.

2. Im Bad von $25^{\circ} \mathrm{C}$. trat ausser bei Nr. 1 innerhalb 1 bis 2 Stunden keine Lackfärbung ein.

3. Im Bad von $40^{\circ}$ C. wurde Nr. 2 nach 13 Minuten, Nr. 3 nach 35 Minuten lackfarben, die anderen nicht.

Bei den Proben mit $8 \%$ Chloralbydrat war nicht allein ein Lackfarbenwerden $z$ beobachten, sondern nach 24 Stunden fand sich auch ein flockiges Sediment aus trüben Coagulis; es hatte demnach das Chloralhydrat auch auf die Eiweisskörper der Blutscheiben verändernd eingewirkt.

Wurde $0,9 \%$ ige $\mathrm{NaCl}-\mathrm{L}$ ösung mit Chloralhydrat versetzt, so wurde ein Tropfen defibrinirten Schweineblutes sofort lackfarben in der $8 \%$ igen und $4 \%$ igen Chloralhydratlösung, in der $2 \%$ igen erst nach 24 Stunden; in der $1 \%$ igen und $0,5 \%$ igen Lösung sedimentirten die Blutscheiben klar, ohne nach 24 Stunden eine Spur lackfarben geworden zu sein. 


\section{Versuche mit Aceton.}

1. Blut mit reinem Aceton versetzt wird in rothen Flocken gefällt.

2. Blut in wässerigen Acetonlösungen verhält sich versehieden. Bei $6-8^{\circ} \mathrm{C}$. löst sich Blut in $25 \%$ iger Lösung von Aceton in Wasser und allen schwächeren Lösungen klar lackfarben. Bei $6-80$ C. bleibt Blut in $37,5 \%$ iger und $50 \%$ iger wässeriger Acetonlösung zunächst deckfarben, in der $37,5 \%$ igen Lösung entsteht unter Lackfarbenwerden gleichzeitig eine Trübung (Ausfällung von Eiweissstoffen), in der $50 \%$ igen Lösung tritt bald Trübung ein, und ein rother Niederschlag sedimentirt.

3. Blut in Mischungen von Aceton und 9,4\%iger Rohrzuckerlösung.

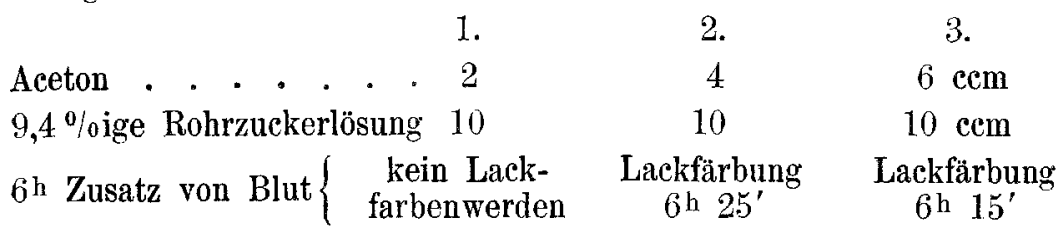

Am nächsten Tag ist Eprouvette 1 klar sedimentirt, keine Auflösung der rothen Blutscheiben, 2 ist vollkommen klar lackfarben, 3 zeigt gefärbte Lösung and rothes flockiges Sediment.

\section{Versuch 12.}

$50 \mathrm{ccm}$ Aceton mit $75 \mathrm{ccm}$ Rohrzuckerlösung geben $120 \mathrm{ccm}$ Gemisch, je $4 \mathrm{ccm}$ dieser Stammlösung $=1,7 \mathrm{ccm}$ Aceton

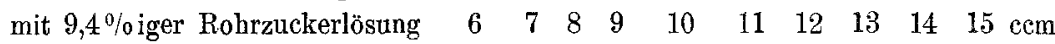
also Aceton ........ 17\% $-1.12 \%---1 \%$ Eprouvette. . . . . . Nr. $\begin{array}{lllllllllll}1 & 2 & 3 & 4 & 5 & 6 & 7 & 8 & 9 & 10\end{array}$

1h $30^{\prime}$ mit 2 Tropfen Fingerblut beschickt: alle sinu deckfarben.

$7 \mathrm{~h}$ n. 1-5 haben Sediment, aber noch keine überstehende Flüssigkeit. 6-10 haben Sediment und einige Cubikmillimeter klare, farblose, überstehende Flüssigkeit.

Alle werden nochmals umgeschüttelt.

Am nächsten Tage nach ca. 16 Stunden sind alle klar sedimentirt.

\section{Versuch 13 und 14.}

Bei der jetzt erfolgten Temperaturprüfung wurde Nr. 1, also Blut in der $17 \%$ igen Aceton-Rohrzuckerlösung, bei $48^{\circ} \mathrm{C}$. lackfarben,

Nr. 5 12\%igen

Nr. $10 \quad 9 \%$ igen

$"$
$" 51^{\circ} \mathrm{C}$. $\quad$ in V. 14 bei $50^{\circ}$
$" 55^{\circ} \mathrm{C}$. $\quad$ in V. 14 bei $55^{\circ}$.




\section{Versuch 15.}

Aceton in 9,4\% iger Rohrzuckerlösung - Fingerblut - $18^{\circ}$ Zimmertemperatur. Aceton $\%$. . . . $50,0 \quad 47,5 \quad 45,5 \quad 42,5 \quad 40,0 \quad 37,5 \quad 35,0$ $\begin{array}{lllllllll}\text { Eprouvette .... Nr. } & 1 & 2 & 3 & 4 & 5 & 6 & 7\end{array}$ 24. Nov. 1802,7 h $30^{\prime}$ A. d. d. lack lack lack lack d. $7 \mathrm{~h} 40^{\prime} \mathrm{A}$. - - - - - - - lack 7h 42' A. Coag. Coag. Coag. trüb trüb - 7 h $50^{\prime}$ A. kl.r.Fl. r. Fl. gr. r. Fl. kl.w. opak trüb 7 h 55' A. r. Sed. Coag. gr. r. gr. r. f. w. opak trüb Sed. Fl. Fl. Fl.

25. Nov. $1902,9^{\mathrm{h}} 00^{\prime} \mathrm{N}$., also nach 14 Stunden:

\begin{tabular}{|c|c|c|c|c|c|c|c|c|}
\hline überstehende 1 & Flüssigkeit & $\begin{array}{c}\text { klar } \\
\text { farblos }\end{array}$ & $\begin{array}{c}\text { kl. } \\
\text { hellgelb }\end{array}$ & $\begin{array}{l}\text { kl. } \\
\text { gelb }\end{array}$ & rothgelb & r. & r. & r. \\
\hline Sediment . & . . . . & $\begin{array}{l}\text { r. u. } \\
\text { gelbe } \\
\text { Fl. }\end{array}$ & $\begin{array}{l}\text { r. u. } \\
\text { gelbe } \\
\text { Fl. }\end{array}$ & $\begin{array}{l}\text { r. u. } \\
\text { gelbe } \\
\text { Fl. }\end{array}$ & $\begin{array}{l}\text { roth- } \\
\text { gelbe } \\
\text { Fl. }\end{array}$ & $\begin{array}{l}\text { weiss- } \\
\text { gelbe } \\
\text { Fl. }\end{array}$ & w. Fl. & w. Fl. \\
\hline Aceton $\%$. & . . . . & 32,5 & 30,0 & 27,5 & 25,0 & 22.5 & 20,0 & 17,5 \\
\hline Epronvette & . . Nr. & 8 & 9 & 10 & 11 & 12 & 13 & 14 \\
\hline 24. Nov. 1902 , & 7 h $30^{\prime}$ A. & d. & d. & d. & d. & d. & d. & d. \\
\hline & $7^{\mathrm{h}} 40^{\prime} \mathrm{A}$. & - & - & - & 一 & 一 & - & - \\
\hline & 7 h $42^{\prime} \mathrm{A}$. & lack & - & - & - & - & - & - \\
\hline & $7 \mathrm{~h} 50^{\prime} \mathrm{A}$ & - & - & - & - & - & 一 & - \\
\hline & $7 \mathrm{~h} 55^{\prime} \mathrm{A}$ & - . & 一 & - & - & - & - & - \\
\hline
\end{tabular}

25. Nov. 1902, 9 h $00^{\prime}$ N., also nach 14 Stunden:

überstehende Flüssigkeit $\quad$ r. $\quad$ r. $\quad$ r. $\quad$ r. gelb kl.w. kl.w. Sediment . . . . . w. Fl. - r. lackf. r. l. roth r. r.

Versuch 16 (genau wie Versuch 15).

\begin{tabular}{|c|c|c|c|c|c|c|c|c|}
\hline Eprouvette & . - Nr. & 1 & 2 & 3 & 4 & 5 & 6 & 7 \\
\hline 24. Nov. 1902 & 7 h $40^{\prime} \mathrm{A}$. & d. & d. & 1.3 & 1.2 & $l_{._{1}}$ & $\mathrm{I}_{4}$ & d. \\
\hline & $7 \mathrm{~h} 45^{\prime} \mathrm{A}$. & trüb & trüb & trüb & trüb & trüb & - & 1. \\
\hline & 7 h 52 A. & kl. r. Fl. & r. Fl. & r. Fl. & opak & opak & opak & - \\
\hline & $7 \mathrm{~h} 58^{\prime} \mathrm{A}$. & sed. & sed. & - & $\begin{array}{l}\text { feinste } \\
\text { Fl. }\end{array}$ & $\begin{array}{c}\text { feinste } \\
\text { Fl. }\end{array}$ & - & - \\
\hline & $8^{\mathrm{h}} 05^{\prime} \mathrm{A}$. & - & - & - & - & - & 一 & 一 \\
\hline 8 h $10^{\prime}\{$ überst. & Flüssigkeit & $\begin{array}{l}\text { farblos } \\
\text { kl. }\end{array}$ & $\begin{array}{c}\text { gelb } \\
\text { kl. }\end{array}$ & $\begin{array}{l}\text { gelb } \\
\text { kl. }\end{array}$ & $\begin{array}{l}\text { r. gelb } \\
\text { kl. }\end{array}$ & $\begin{array}{l}\text { r. } \\
\text { kl. }\end{array}$ & $\underset{\text { trüb }}{\mathrm{r} .}$ & $\begin{array}{l}\text { r. } \\
\text { trüb }\end{array}$ \\
\hline $\begin{array}{r}\text { ISedime } \\
\text { ur }\end{array}$ & $\begin{array}{l}\text { nt: oben. } \\
\text { ten ... }\end{array}$ & $\begin{array}{l}\text { braun } \\
\text { r. }\end{array}$ & $\begin{array}{l}\text { braun } \\
\text { r. }\end{array}$ & $\begin{array}{c}\text { hellbraun } \\
\text { r. }\end{array}$ & $\begin{array}{l}\text { w. } \\
\text { r. }\end{array}$ & $\begin{array}{c}\text { w. } \\
\text { bräunlich }\end{array}$ & $\begin{array}{l}\text { w. } \\
\text { w. }\end{array}$ & $\begin{array}{l}\text { w. } \\
\text { w. }\end{array}$ \\
\hline Eprouvette & . . Nr. & 8 & 9 & 10 & 11 & 12 & 13 & 14 \\
\hline & 7 h $40^{\prime}$ A. & d. & d. & d. & d. & d. & d. & d. \\
\hline & $7 \mathrm{~h} 45^{\prime}$ A. & I. & - & - & - & - & 一 & - \\
\hline & $7 \mathrm{~h} 52^{\prime} A$. & - & - & - & - & - & - & - \\
\hline & $7 \mathrm{~h} 58^{\prime}$ A. & 一 & - & - & - & - & - & 一 \\
\hline & $8 \mathrm{~h} 05^{\prime} \mathrm{A}$. & - & 1. & - & - & - & 一 & - \\
\hline
\end{tabular}


$\begin{array}{llllllllll}\text { Eprouvette . . . . Nr. } & 8 & 9 & 10 & 11 & 12 & 13 & 14\end{array}$

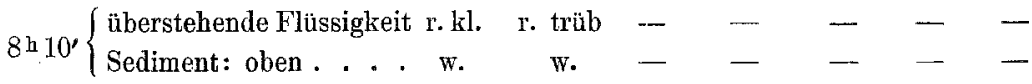
unten .... - $\quad$ - - - - - - - -

Abkürzungen: $\mathrm{d} .=$ deckfarben; Coag. $=$ Coagula; $\mathrm{r} .=$ roth; gr. $=$ gross; Fl. = Flocken; I. = lackfarben; Sed. = Sediment: w. = weiss; $\mathrm{kl}$. = klein.

\section{Versuch 17.}

Aceton in $0,9 \%$ iger NaCl-Lösung: Fingerblut; Zimmertemperatur $8,5{ }^{\circ} \mathrm{C}$.

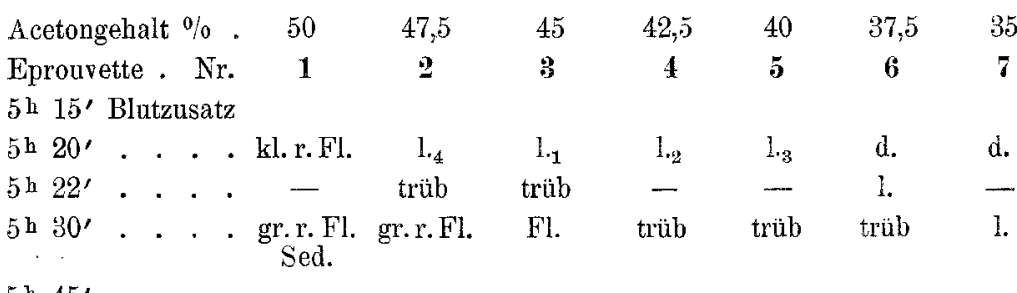

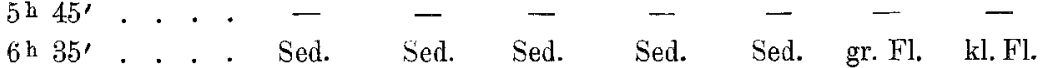
am nächsten Tage gr. Fl. gr. Fl. gr. Fl. gr. Fl, gr. Fl. gr. Fl. gr. Fl.

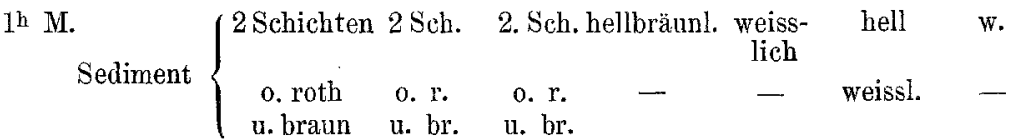
überst. Fl. . . klar w. klar gelb röthl. roth r. r. r.

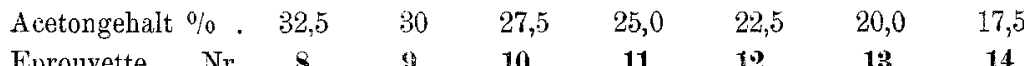
$\begin{array}{llllllll}\text { Eprouvette . Nr. } & 8 & 9 & 10 & 11 & 12 & 13 & 14\end{array}$ 5 h $15^{\prime}$ Blutzusatz 5 h $20^{\prime}$. . . 8-14 deckfarben

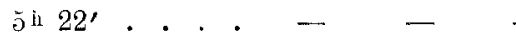

l. r. Sed. r. Sed. r. Sed. keine Lackfarbe am ıächsten Tage kl.Fl. $\quad$ - $\quad$ - $\quad$ - dunkelrother r. Sed. beginnt 1 h $\mathrm{M}$

$$
\text { kl. Fl. - - - } \begin{gathered}
\text { dunkeirother } \\
\text { lack. Bodensatz }
\end{gathered}
$$
l. z. werden.

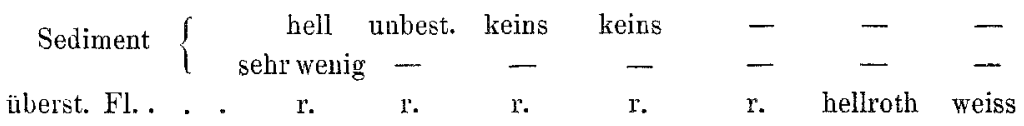

\section{Versuch 18.}

Aceton in $0,9 \%$ iger $\mathrm{NaCl}$-Lösuug. In $9,4 \%$ iger Zuckerlösung gewaschene rothe Blutscheiben vom Hund. Z.-Tp. $5,8^{\circ}$. Verlauf genau wie beim vorigen Versuch, jedoch war das Sediment in den Eprouvetten 1-3 nicht zweischichtig und in $1-6$ stets roth. 
Einfluss der Temperatur auf rothe Blutscheiben in Acetongemischen.

\section{Versuch 19.}

Bei $18^{\circ}$ Zimmertemperatur werden 5 Aceton-Rohrzuck er lösungsgemische (17,5-27,5\% Aceton) mit rothen Blutscheiben (Fingerblut) versetzt.

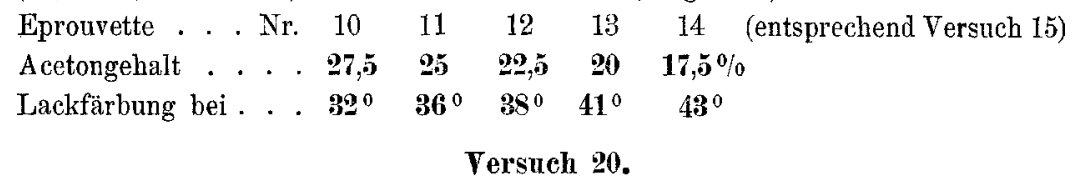

Bei $18^{0}$ Zimmertemperatur wurden 4 Aceton-NaCl-Lösungsgemische (2.5 bis $17,5 \%$ Aceton) mit Fingerblut versetzt und sofort im Wasserbad steigender Temperatur ausgesetzt.

Eprouvette . . . . . Nr. $11 \quad 12 \quad 13 \quad 14 \quad$ (entsprechend Versuch 17)

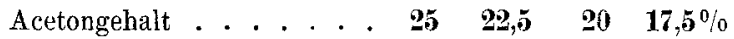

Lackfärbung bei . . . . $3 \xi^{0} 40-41^{0} \quad 46^{\circ} \quad 49^{\circ}$

1. Aceton ist nicht im Stande, die Schädigung der rothen Blutscheiben aufzuheben.

2. Aceton in genügender Concentration fällt Stoffe der in Wasser gelösten Blutscheiben aus.

3. In neutraler Rohrzuckerlösung und neutraler NaCl-Lösung wirkt Aceton Blutkörperchen auflösend, o hne Stoffe auszufällen in Rohrzuckerlösung bei $25-30 \%$, in $\mathrm{NaCl}$ bei $25-30 \%$ Acetongehalt.

4. In neutralen Rohrzuckerlösungen und $\mathrm{NaCl-Lösung} \mathrm{wirkt}$ Aceton bei gewöhnlicher Temperatur nicht schädigend auf die rothen Blutscheiben, so dass keine Auflösung eintritt bei einem Acetongehalt untex 17,5 ${ }^{\circ}, 0$; bei einem Acetongehalt von 17,5-27,5\% tritt Auflösung der Blutscheiben erst nach längerer Zeit, über 14 Stundẹn, ein.

5. Bei diesem geringeren Acetongehalt wirkt das Aceton rascher auflösend bei höherer Temperatur, und zwar je weniger Acetongehalt vorhanden, desto höher muss die Temperatur sein, um Auflösung der rothen Blutscheiben hervorzurufen: bei 27,5\% Acetongehalt trat Lackfarbenwerden ein bei $32^{\circ} \mathrm{C}$, , bei $9 \%$ Aceton bei $55^{\circ} \mathrm{C}$.

\section{Versuche mit Alkohol.}

Versuch 21.

$10 \mathrm{ccm}$ Wasser mit ansteigenden Mengen Alkohol absol. gemischt. Aq. dest. je $10 \mathrm{ccm}$.

Alkohol abs. ccm . . . 5 5 6 ; 8

Eprouvette . . . . . . $1122 \quad 3 \quad 4$

$2^{\mathrm{h}} 45^{\prime}$ Fingerblut. . . lack lack lack lack

$6 \mathrm{~h}^{\mathrm{h}} 30^{\prime}$. . . . . . lack lack lack lack

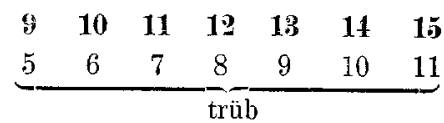

opak in Folge feinster Coagula 
Am nächsten Tage $12 \mathrm{~h} \mathrm{~V}$, also nach 21 Stunden

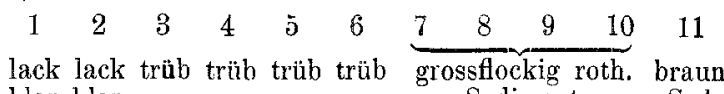

$$
\begin{aligned}
& \text { klar klar } \\
& \text { Sediment, Sed. } \\
& \text { überst. Fl. gelblich. }
\end{aligned}
$$

Versuch 29.

Alkohol absol. in 9,4\% iger Rohrzuckerlösung. Rohrzuckerlösung $20 \mathrm{ccm}$; Zimmertemperatur $8^{\circ} \mathrm{C}$; Fingerblut $12^{\mathrm{h}} 10^{\prime}$ zugesetzt.

$\begin{array}{lllllllllll}\text { Alkohol. absol. ccm. . . . . } & 3 & 4 & 5 & 6 & 7 & 8 & 9 & 10 & 11\end{array}$

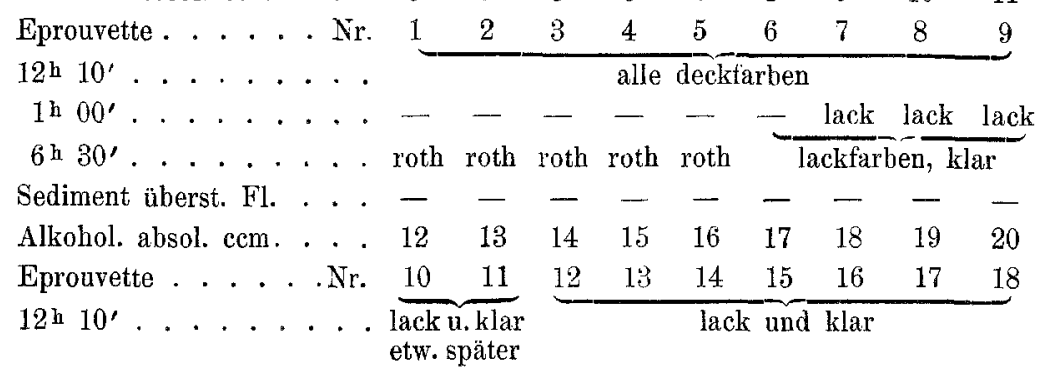

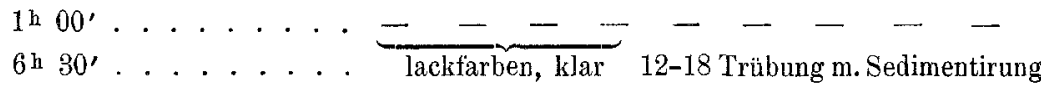
am nächsten Tage $12 \mathrm{~h}$ V., also nach 24 Stunden

1-4 roth Sed. überst. Fl. klar, farblos. 5 u. 6 lackf. aber trüb. 7-12 lackfarben, klar, roth. 13-18 grossflock. Sediment, überst. Fl. roth bis gelblich.

Ueberstehende Flüssigkeit bei 1-4 d u r ch Centrifugiren klar; bei 13-18 trotz Centrifugiren nicht klar, sondern opak durchscheinend bis opak undurchsichtig.

\section{Versuch 28.}

Bei Mischungen von $20 \mathrm{ccm}$ Robrzuckerlösung mit $3-6 \mathrm{~cm}$ Alkoh. abs. bleibt das Blut deckfarben bei gewöhnlicher Temperatur; wie verbält es sich bei höherer Temperatur?

Rohrzuckerlösung . . . . . . $20 \mathrm{ccm}$

Alkohol absol. . . . . . . . . . 30 3 4 a 6 ccm

$\begin{array}{llll}1 & 2 & 3 & 4\end{array}$

Blut wird lackfarben bei . . . . 50-52 ${ }^{0}$ C. $\quad \mathbf{4 6}^{\circ} \quad \mathbf{4 0 - 4 1 ^ { 0 }} \quad \mathbf{3 8 ^ { \circ }}$

Die Versuchsresultate mit Alkohol gleichen im Wesentlichen den mit Aceton; für das, was zunächst in Betracht kommt, genügen diese Versuche; über weitere Einzelheiten wird im Anschluss an andere Versucbe berichtet werden, bei denen noch auf eine genauere Bestimmung des Alkoholgehaltes der Lösungen gesehen wurde, die hier, wo es sich nur um Vergleichszahlen handelte, unterblieb.

Besprechung der Versuche.

Mehr oder weniger vollkommen wirken, wie die angeführten Versuche ergeben, eine Reihe von Stoffen schädigend auf rothe Blut- 
scheiben ein, so dass Lackfarhenwerden derselben eintritt. Diese Stoffe sind Aether, Chloroform, Schwefelkohlenstoff, Toluol, Xylol, Aceton, Alkohol, Chloralbydrat. Von diesen eine gemeinsame Eigenschaft ausfindig zu machen, welche mit der Erscheinung des Lackfarbenwerdens der rothen Blutscheiben iu ursächlichen $\mathrm{Zu}$ sammenhang gebracht werden könnte, hat Schwierigkeit. Das Einzige, was allen gemeinsam ist, wäre die Fähigkeit, Fette zu lösen.

Dieser Umstand lenkt unsere Vorstellungen in ganz bestimmte Bahnen, denn das wären demnach die Stoffe, welche einen Schluss auf die chemische Natur der "Wand" der rothen Blutscheiben gestatten.

Wir brauchen noch nicht einmal anzunehmen, dass die "Wand" der rothen Blutscheiben aus einem Fette oder fettähnlichem Stoffe bestehe, sondern nur, dass ein Fett oder fettähnlicher Stoff ein wesentlicher Bestandtheil der "halbdurchlässigen Wand" der rothen Blutkörperchen ist, und das Lackfarbenwerden rother Blutscheiben durch Aether, Chloroform, Schwefelkohlenstoff, Toluol, Xylol, Aceton, Alkohol und Chloralhydrat erklärt sich höchst einfach dadurch, dass eben diese Stoffe die schützende halbdurchlässige Wand der Blutkörperchen a uflösen.

\section{Allgemeine Zusammenfassung der Versuchsergebnisse.}

Fassen wir die Versuchsresultate summarisch zusammen, so könnten wir feststellen:

Die rothen Blutscheiben werden lackfarben:

1. durch Wasser, 2. durch Wärme, 3. durch Wasserstoffionen, 4. durch Hydroxylionen, 5. durch eine Reilhe von Stoffen, welche Fette lösen.

In allen diesen Fällen beobachten wir die gleiche Erscheinung; es fragt sich, ob sich bei allen der gleiche Vorgang abspielt, und ob bei allen die gleiche Ursache vorliegt!

Das Lackfarbenwerden des Blutes durch Wasser hatten wir zurückgeführt auf das durch den übergrossen Unterschied des osmotischen Druckes innerhalb und ausserhalb der rothen Blutscheiben entstehende Quellen und schliessliche Platzen der Blutkörperchen, also in letzter Linie auf die Zerstörung der halbdurchlässigen Wand. 
Das Lackfarbenwerden des Blutes durch Aether, Chloroform, Aceton, Alkobol u. s. w., also Stoffe, welche Fette zu lösen im Stande sind, bringt uns auf die Vermuthung, dass die halbdurchlässige Wand der rothen Blutscheiben aus einem fettähnlichen Körper bestehe oder einen solchen enthalte.

Eine solche fettähnliche Wand wird aber auch in der Wärme schmelzen, dadurch zu Grunde gehen, und Lackfarbenwerden des Blutes ist die Folge. Die relative Konstanz der Temperatur, bei welcher Lackfärbung auftritt, steht in guter Uebereinstimmung mit der Konstanz des Schmelzpunktes von Fetten. Nun bleibt noch übrig, die Wirkung der Wasserstoffionen und der Hydroxylionen zu erklären :

Wasserstoffionen beschleunigen die Spaltung eines Esters in verdünnter wässeriger Lösung in den betreffenden Alkohol und die betreffende Säure, ein Vorgang der als Kataly se bezeichnet wird; durch Hydroxylionen erfolgt Verseifung der Ester, d. h. aus dem Ester bildet sich der betreffende Alkohol und das Salz aus dem negativen Bestandtheil des Esters und dem positiven Bestandtheil der verwendeten Base.

Die beim Lackfarbenwerden rother Blutscheiben durch Säuren und durch Basen beobachteten Gesetzmässigkeiten zeigten in der That eine auffallende Aehnlichkeit mit der Katalyse resp. Verseifung eines Esters. So gelangen wir zu der zweiten Hypothese:

Die halbdurchlässige Wand der rothen Blutscheiben besteht aus einem fettähnlichen Stoff oder enthält einen solchen Stoff als wesentlichen Bestandtheil.

Eine solche halbdurchlässige Wand kann durch Wärme sehmelzen, in Chloroform, $\mathrm{CS}_{2}$, Aether u. s. w. sich auflösen, durch Wasserstoffionen katalysirt, dureh Hydroxylionen verse ift werden.

Die verschiedenen Energieformen, welche diese verschiedenen Vorgänge, das Quellen und Platzen, das Schmelzen, das Auflösen, die Katalyse, die Verseifung der halbdurchlässigen Wand, bewirken, sie zerstören alle diese "Wand" oder ihre Eigenschaft, halbdurchlässig zu sein, und in Folge dessen wird das Blut lackfarben. D i e Ursache des Lackfarbenwerdens der rothen Blutscheiben ist also schliesslich doch eine einheitliche: Zerstörung der halbdurehlässigen Wand. 
Unsere erste Hypothese:

I. Die rothen Blutscheiben sind von einer halbdurchlässigen Wand umgeben, ist durch die vorliegenden Untersuchungen in keinem Punkte widerlegt worden, sie steht mit den Beobachtungen in gutem Einklang. Sie ist erweitert worden durch eine zweite Hypothese:

II. Die halbdurehlässige Wand der rothen Blutscheiben besteht aus einem fettähnlichen Stoffe oder enthält einen solchen Stoff als wesentlichen Bestandtheil (Lecithin - Cholesterin?), und als dritte Hypothese fügt sich diese an:

III. Zerstörung der halbdurchlässigen Wand macht die rothen Blutscheiben lackfarben.

Ueber die Structur der "halbdurchlässigen Wand", ob Membran, ob Wabengerüst oder dergleichen, ergaben diese Untersuchungen wieder nichts. Die Vorstellung eines rothen Blutscheibchens als eine mit flüssigem Inhalt gefüllte Blase ist eine vollkommen willkürliche, welche den beobachteten Erscheinungen sich zwar sehr gut anpasst, aber der Wirklichkeit nicht zu entsprechen braucht.

Weitere, die angeführten Hypothesen theils stützende, theils weiter ausbauende Untersuchungen sind erst theilweise beendet; dieselben werden in einer demnächst erscheinenden zweiten Mittheilung veröffentlicht werden.

\section{Schlussbetrachtung.}

Unsere hypothetische Vorstellung von einer halbdurchlässigen Wand der rothen Blutscheiben und die dementsprechende physikalischchemische Betrachtung der beobachteten Vorgänge hat sich durchaus bewährt und fruchtbar bewiesen, indem sie ganz bestimmte Direktiven für neue Untersuchungen ergab. In durchaus logischer Weise auf den gewonnenen Grundanschauungen weiter bauend, sind wir zu neuen Versuchen, neuen Resultaten gekommen.

Diese neuen Resultate, von allem Hypothetischen losgelöst, verdienen aber an sich unsere volle Beachtung.

Wenn unsere Untersuchungen ergaben, dass rothe Blutscheiben lackfarben werden durch 1. Wasser, 2. Wärme, 3. eine Reihe von Stoffen, welche Fett lösen, 4. durch Säuren, 5. durch Basen, also eine ziemliche Reihe von Agentien sich als "hämolytisch" wirkend 
erwiesen, so bestehen doch zwischen denselben mancherlei Verschiedenheiten.

1. Damit Wärme hämolytisch wirkt, ist eine bestimmte Menge nothwendig, eine bestimmte Concentration des Agens; wird diese nicht erreicht, so tritt kein Lackfarbenwerden ein, gleichgültig, wie lange gewartet wird, dagegen erfolgt der Umschlag fast sofort, wenn der Schwellwerth erreicht ist. Gleichgültig ist, ob die Wärmezufuhr rasch oder langsam erfolgt.

2. Das beim Lackfarbenwerden durch W asser wirksame hämolytische Agens ist der osmotische Ueberdruck innerhalb der Blutscheiben gegen den der Ungebung. Auch von diesem Ueberdruck ist eine bestimmte, wenn auch geringe Menge nöthig, um Hämolyse herbeizuführen. Die Concentration des Agens ist allein maassgebend, wenigstens ist kein Factor nachweisbar, welcher beeinflussend mit wirkt.

3. Ein wesentlich anderes Resultat ergibt sich bei Betrachtung der verschiedenen Versuche mit Stoffen, welche Fett lösen (also Aether u. s. w.). Bei allen diesen Stoffen, welche wir direct als das hämolytische Agens ansehen müssen, ist die Menge der Concentration von ausschlaggebendem Einfluss. Allein es ist noch ein zweiter Factor nöthig, der mitwirken muss, damit Hämolyse eintritt; das ist die Temperatur.

Das hämolytische Agens an sich ist unwirksam, wenn die zur Reaction nöthige Temperatur nicht erreicht ist. Eine an sich unwirksame Menge des hämolytischen Agens wird wirksam, weun die Temperatur entsprechend erhöht wird. Wenn die zur Hänolyse nöthige Concentration des Agens und die zu dieser Concentration gehörige Temperatur nicht vorhanden sind, tritt auch keine Hämolyse ein, gleichgültig, wie lange das ungenügende Agens einwirkt. (Versuch Abschnitt 8 Nr. 7 ergibt ein scheinbar widersprechendes Resultat, doch kommen hier noch andere Momente in Betracht.)

4. Die Wirkung von Wasserstoffionen und Hydroxylionen als hämolytisches Agens ist durch einen Factor mehr beeinflusst. Damit H- und OH-Ionen hämolytisch wirken, ist nöthig, dass dieses hämolytische Agens erstens in genügender Concentration vorhanden ist, zweitens, dass eine bestimmte Temperatur besteht, und drittens eine gewisse $\mathrm{Z}$ eit gewährt wird zur Einwirkung.

Diese drei Factoren stehen in einem gewissen Verbältniss zu 
einander. Eine bestimmte Concentration von H-Ionen wirkt erst hämolytisch, wenn bei einer bestimmten Temperatur eine dieser Temperatur entsprechende Zeitdauer der Einwirkung gestattet wird. Es bestehen dabei folgende Beziehungen:

1. Bei gleicher Temperatur wirkt die stärkere Concentration schneller als die schwache.

2. Bei gleicher Concentration des Agens erfolgt die Hämolyse um so schneller, je höher die Temperatur.

3. Um innerhalb einer bestimmten Zeit Hämolyse zu erhalten, kann eine an sich unwirksame Concentration durch Erhöhung der Temperatur wirksam gemacht werden und bei ungenügender Temperatur durch Erhöhung der Concentration Hämolyse hervorgerufen werden.

Beim Lackfarbenwerden der rothen Blutscheiben durch $W$ ärme ist allein die absolute Menge maassgebend; bei der Hämolyse durch osmotische Energie kommen schon nicht mehr absolute Mengenwerthe in Betracht, sondern nur die Differenz zweier osmotischer Druckgrössen; bei der Hämolyse durch Aether und dergleichen Stoffe ist die Quantität des Agens zwar von Belang, aber nicht ausschlaggebend, ein $z$ weiter Factor: die Temperatur, spielt eine bedeutende Rolle; schliesslich bei der Hämolyse durch $\mathrm{H}$ - oder $\mathrm{OH}$ Ionen stehen drei $\mathrm{F}$ actoren in gewisser gesetzmässiger Beziehung $\mathrm{zu}$ einander, nämlich $\mathrm{C}$ oncentration, Temperatur und Zeit.

Unter physiologischen Verhältnissen kann eine Hämolyse in Folge Wärme nicht in Betracht kommen, weil Temperaturen über $68^{\circ}$ nicht erreicht werden; ebenso ist eine Schädigung rother Blutscheiben in Folge osmotischen Druckunterschieds praktisch belanglos. Die schädigende Wirkung von Wasserinfusionen ist bekannt.

Von hervorragendem Interesse aber sind die Ergebnisse der Versuche mit Aether und dergleichen Stoffen, sowie die Resultate der Untersuchungen der Wirkung der $\mathrm{H}-$ und OH-Ionen. Ein weiteres Eingehen auf diese Ergebnisse und daraus zu ziehende Schlüsse erscheint mir noch nicht am Platze, bevor nicht die Untersuchungen beendet sind, welche eine Reihe von Begleiterscheinungen betreffen, durch die u. A. die gefundenen Gesetzmässigkeiten beeinflusst werden. 